OPEN ACCESS

Edited by:

Atsushi Otsuka,

Kyoto University, Japan

Reviewed by:

Hiroshi Uchi

Kyushu University, Japan

Oleg E. Akilov,

University of Pittsburgh, United States

*Correspondence:

Yoshiyuki Nakamura ynakamura-tuk@umin.ac.jp

Specialty section:

This article was submitted to

Dermatology,

a section of the journal

Frontiers in Medicine

Received: 27 March 2019

Accepted: 15 May 2019

Published: 29 May 2019

Citation:

Nakamura Y (2019) Biomarkers for Immune Checkpoint

Inhibitor-Mediated Tumor Response

and Adverse Events.

Front. Med. 6:119.

doi: 10.3389/fmed.2019.00119

\section{Biomarkers for Immune Checkpoint Inhibitor-Mediated Tumor Response and Adverse Events}

\author{
Yoshiyuki Nakamura* \\ Department of Dermatology, Faculty of Medicine, University of Tsukuba, Tsukuba, Japan
}

In the last decade, inhibitors targeting immune checkpoint molecules such as cytotoxic T-lymphocyte antigen 4 (CTLA-4), programmed cell death 1 (PD-1), and programmed cell death-ligand 1 (PD-L1) brought about a major paradigm shift in cancer treatment. These immune checkpoint inhibitors (ICls) improved the overall survival of a variety of cancer such as malignant melanoma and non-small lung cancer. In addition, numerous clinical trials for additional indication of ICls including adjuvant and neo-adjuvant therapies are also currently ongoing. Therefore, more and more patients will receive ICls in the future. However, despite the improved outcome of the cancer treatment by ICls, the efficacy remains still limited and tumor regression have not been obtained in many cancer patients. In addition, treatment with ICls is also associated with substantial toxicities, described as immune-related adverse events (irAEs). Therefore, biomarkers to predict tumor response and occurrence of irAEs by the treatment with ICls are required to avoid overtreatment of ICls and minimize irAEs development. Whereas, numerous factors have been reported as potential biomarkers for tumor response to ICls, factors for predicting irAE have been less reported. In this review, we show recent advances in the understanding of biomarkers for tumor response and occurrence of irAEs in cancer patients treated with ICls.

Keywords: immune check point inhibitor, adverse event (AE), PD-1, CTLA- 4, tumor response

\section{INTRODUCTION}

The recent development of immune checkpoint inhibitors (ICIs) has led to dramatic advances in cancer therapy. Ipilimumab is a monoclonal antibody to cytotoxic T-lymphocyte antigen 4 (CTLA4), an inhibitory receptor expressed by both conventional and regulatory $\mathrm{T}$ cells (Tregs) and suppresses $\mathrm{T}$ cell activation by competing with $\mathrm{CD} 28$ to bind CD80/86. Ipilimumab not only activates conventional $\mathrm{T}$ cells at the initial stage of maturation but also may show antibodydependent cell-mediated lysis of the Tregs that play a vital role in suppressing the antitumor immune response $(1,2)$. Programmed cell death 1 (PD-1) is an inhibitory receptor expressed mainly by activated T cells and its ligand, PD-L1, is widely expressed in cell types as diverse as epithelial cells, immune cells, and cancer cells. Both anti-PD-1 antibodies (nivolumab and pembrolizumab) and anti-PD-L1 antibodies (atezolizumab, durvalumab, and avelumab) exert antitumor effects by activating previously primed $\mathrm{T}$ cells which have lost effector and proliferative functions (3). ICIs firstly demonstrated efficacy for patients with advanced melanoma (4-6) and subsequently in other cancers, such as non-small cell lung cancer (NSCLC) and renal cell carcinoma (7-9). A recent clinical trial revealed that adjuvant therapies with anti-PD-1 antibodies prolonged 
recurrence-free survival in resected high-risk melanoma (1012). Moreover, there are currently ongoing trials for neoadjuvant therapies with anti-PD-1 antibodies in high risk resectable melanoma $(11,13)$. Numerous clinical trials testing additional indications of ICIs for other cancers are also ongoing $(14,15)$. Therefore, an ever-increasing number of patients will receive ICIs in the near future.

However, despite an improved overall survival (OS) with ICIs, the efficacy remains limited and tumor regression has not been universally achieved (16). In addition, use of ICIs may induce unique side effects, described as immune-related adverse events (irAEs). In a previous melanoma phase III clinical trial, patients who received nivolumab alone $(n=313)$, ipilimumab alone $(n=311)$ or nivolumab plus ipilimumab $(n=313)$ saw irAEs of grade 3 or 4 occurring at a rate of 21,28 , and $59 \%$, respectively, and four patients died due to severe irAEs (16). Therefore, biomarkers to predict tumor response and irAE occurrence due to ICIs are necessary to gauge the benefits that each patient will obtain for avoiding overtreatment and minimizing irAEs. Here, we review recent advances in the understanding of biomarkers for tumor response and irAE occurrences.

\section{Biomarkers for Tumor Response (Table 1)}

Numerous factors have been reported as potential biomarkers for objective response rate (ORR), progression free survival (PFS) or OS. However, non-specific factors, which are associated with tumor responses to not only ICIs but also other therapies (such as traditional chemotherapies), can confound the use of these biomarkers. Therefore, specificity as well as correlative strength should be considered in choosing ICIs over other therapies.

\section{Sex}

Several studies have demonstrated that sex differences are associated with anti-tumor immune responses $(70,71)$. Although many clinical studies did not show a correlation between sex and tumor response to ICIs, meta-analyses with larger numbers of melanoma and NSCLC patients who were treated with ICIs revealed that both the PFS and OS of male patients were significantly longer than those of female patients (17). Based on a subtype analysis, sex differences in OS were greater in melanoma patients than NSCLC patients. In addition, in the anti-CTLA-4 antibodies group, the OS difference between male and female was greater than in the anti-PD-1 antibodies group. In line with this result, another study demonstrated that males were significantly associated with better ORR in melanoma patients treated with anti-PD-1 antibodies (18). Therefore, males seem to benefit more from ICIs than females do although the mechanism behind this effect has yet to be clarified.

\section{Age}

A recent preclinical study demonstrated that tumor response to anti-PD-1 antibodies in aged mice was significantly increased compared to younger mice, an effect attributed to the lower proportion of Tregs in aged mice (72). Consistent with these results, the tumor response to pembrolizumab in melanoma patients over age 60 was significantly higher than those under 60 years and the likelihood of response increased with age (72).
Similarly, Nosrati et al showed that ages older than 65 years correlated with better ORR in melanoma patients treated with anti-PD-1 antibodies (18). However, opposite results have also been reported and a meta-analysis by Nishijima et al revealed a correlation between ages younger than 75 years with better ORR in patients treated with ICIs (19). Therefore, further studies are needed to evaluate the usefulness of age as a biomarker for ICI response.

\section{Tumor Size}

Huang et al. reported that reinvigoration of exhausted CD8 T cells $\left(\mathrm{T}_{\mathrm{ex}}\right.$-cell $)$ positively correlated with tumor size and the ratio of $\mathrm{T}_{\mathrm{ex}}$-cell reinvigoration to tumor size was significantly associated with better ORR and longer OS in melanoma patients treated with pembrolizumab (73), indicating that tumor size is a predictive factor for poor response to ICI treatments. Indeed, another study demonstrated that tumor size was independently associated with OS in melanoma patients treated with pembrolizumab although it was associated with many other clinical factors (20). Therefore, early detection of metastatic lesions may be important for better response to ICIs.

\section{Immune Cell Infiltration}

Because ICIs activate the immune response to cancer, infiltration of immune cells, including T cells, into tumors may induce tumor regression following treatment. Generally, higher numbers of tumor infiltrating lymphocytes (TILs) have been a favorable prognostic factor in many types of cancers, such as melanoma and colorectal cancer $(74,75)$. Similarly, Tumeh et al revealed that presence of $\mathrm{CD}^{+}$TILs at the invasive margin, which was associated with higher PD-1/PD-L1 expression, correlated with better tumor response in melanoma patients treated with pembrolizumab (21). An increase in $\mathrm{CD}^{+}$TILs from baseline to post-treatment biopsy, specifically at the tumor center and invasive margin, has been also significantly associated with tumor regression (21). Therefore, both baseline and post-treatment TIL numbers may be important biomarkers for predicting tumor response to ICIs.

\section{Surface Molecules and Their Related Molecules PD-L1}

Since PD-L1 is a ligand of PD-1 and serves an inhibitory signal in PD-1 expressing cells, the expression of PD-L1 in tumor environments is speculated to correlate with better response in patients treated with anti-PD-1 antibodies. Indeed, in melanoma clinical trials with anti-PD-1 antibodies, better outcomes were observed in patients with positive PD-L1 expression in tumors although the definition of positive or negative expression differed across studies $(22,23)$. Higher PD-L1 expression has also been associated with better outcomes in NSCLC patients treated with anti-PD-1 antibodies (24). In addition, a recent clinical trial demonstrated that combinations of nivolumab with ipilimumab showed a better OS than nivolumab monotherapy in melanoma patients with $\mathrm{PD}-\mathrm{L} 1<1 \%$, whereas the OS was comparable between the 2 treatment groups in patients with $\mathrm{PD}-\mathrm{L} 1 \geq 1 \%$, suggesting that anti-PD-1 antibody efficacy is largely dependent 
离

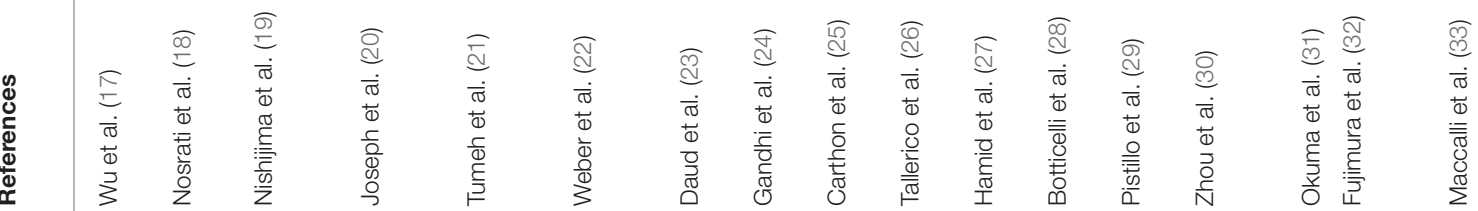

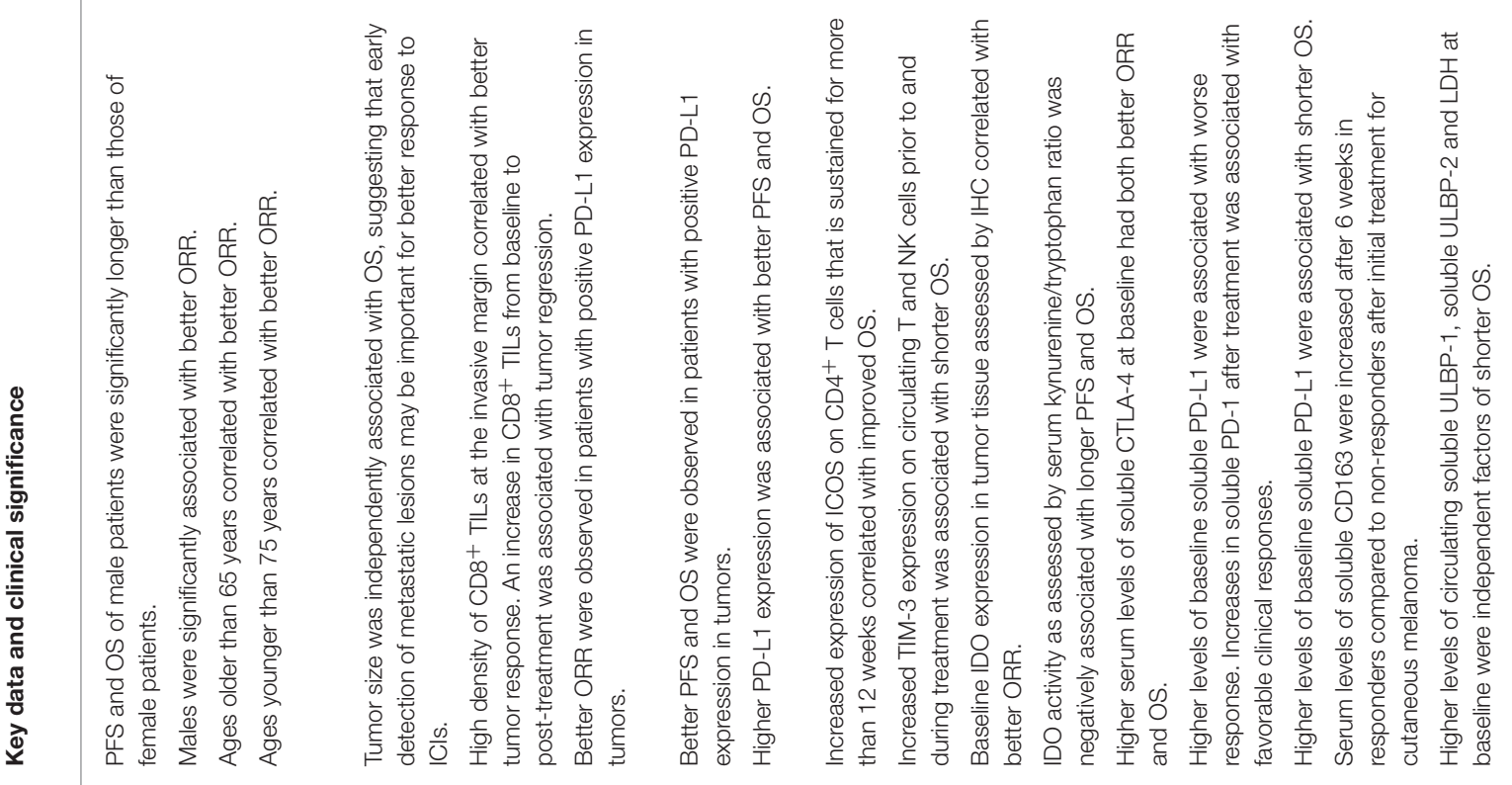

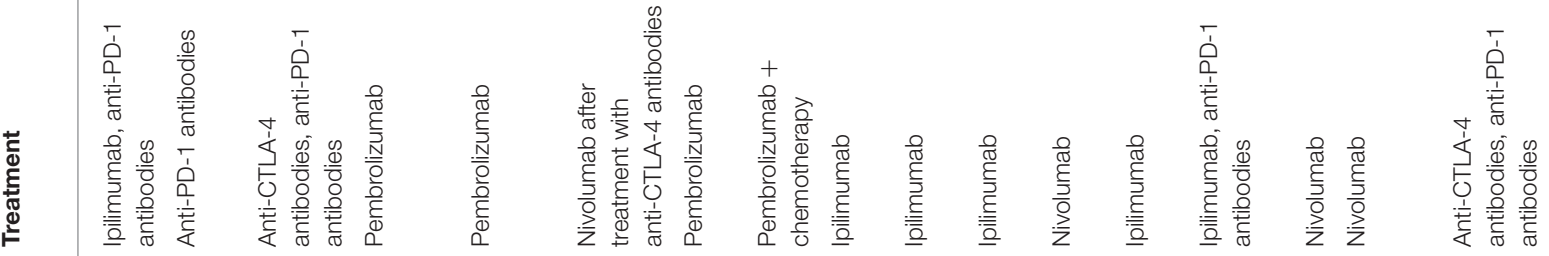

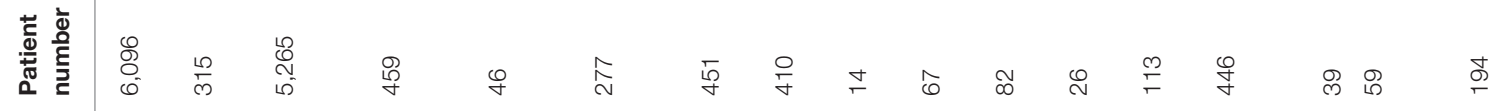
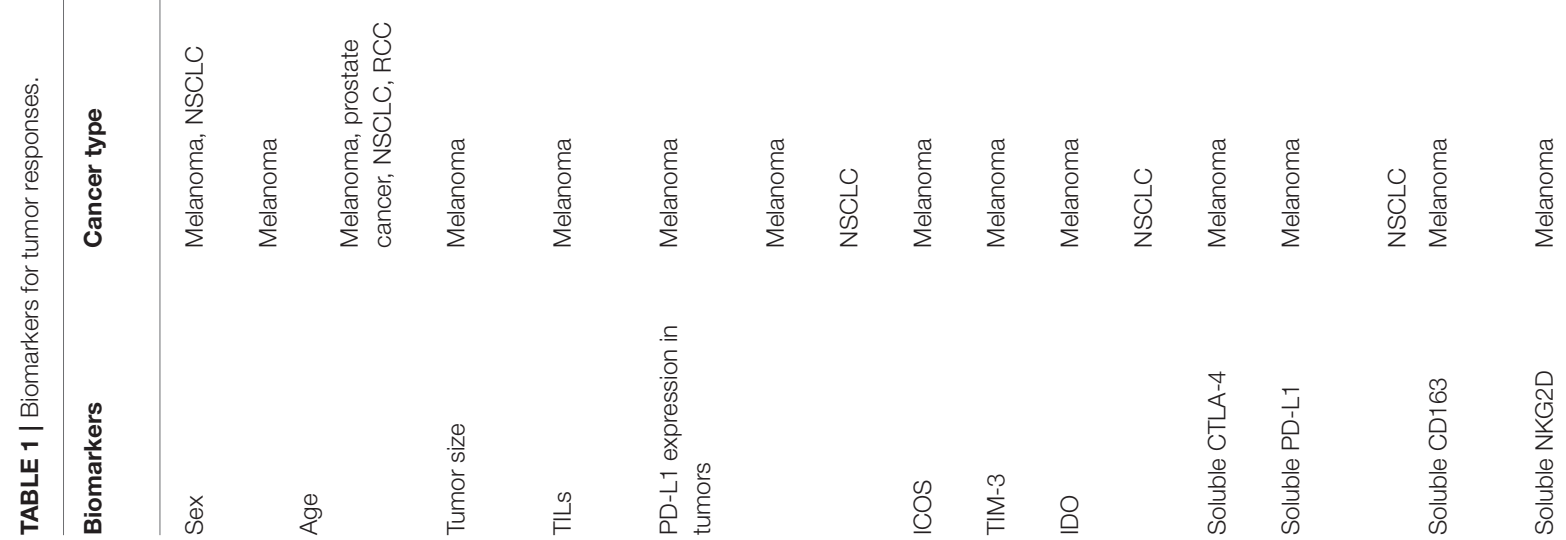


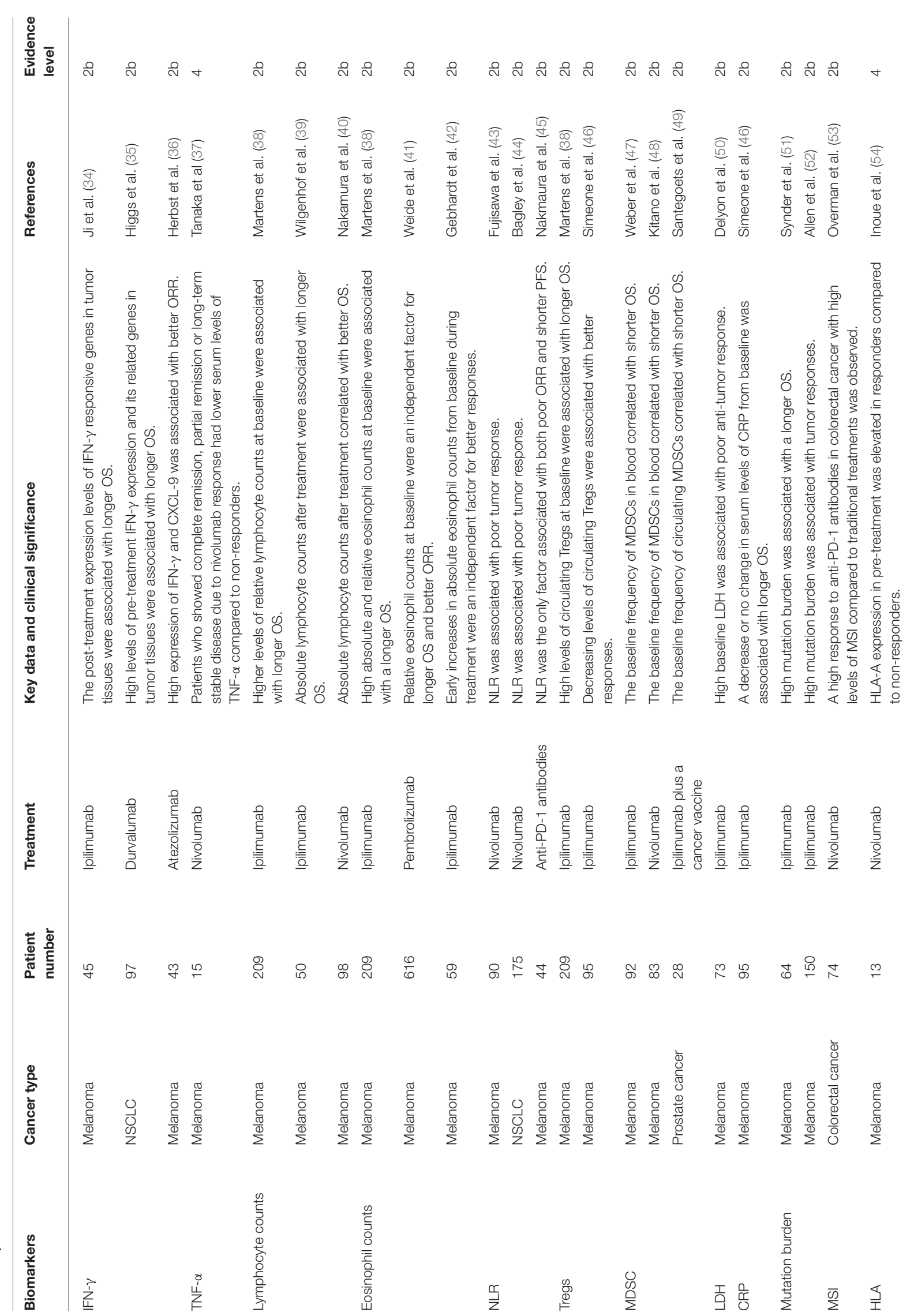




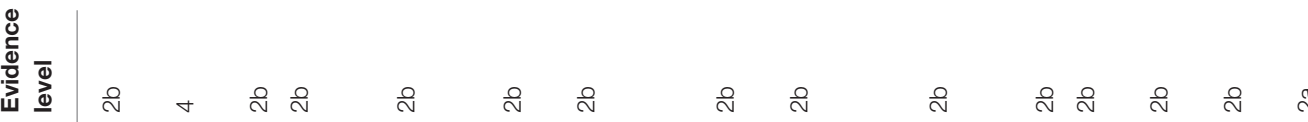

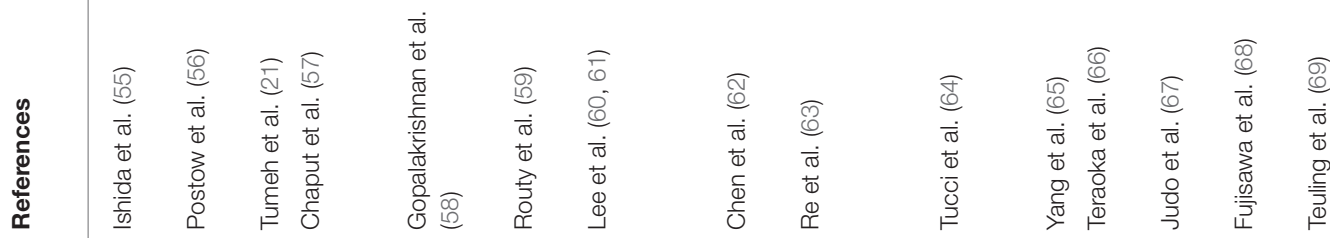

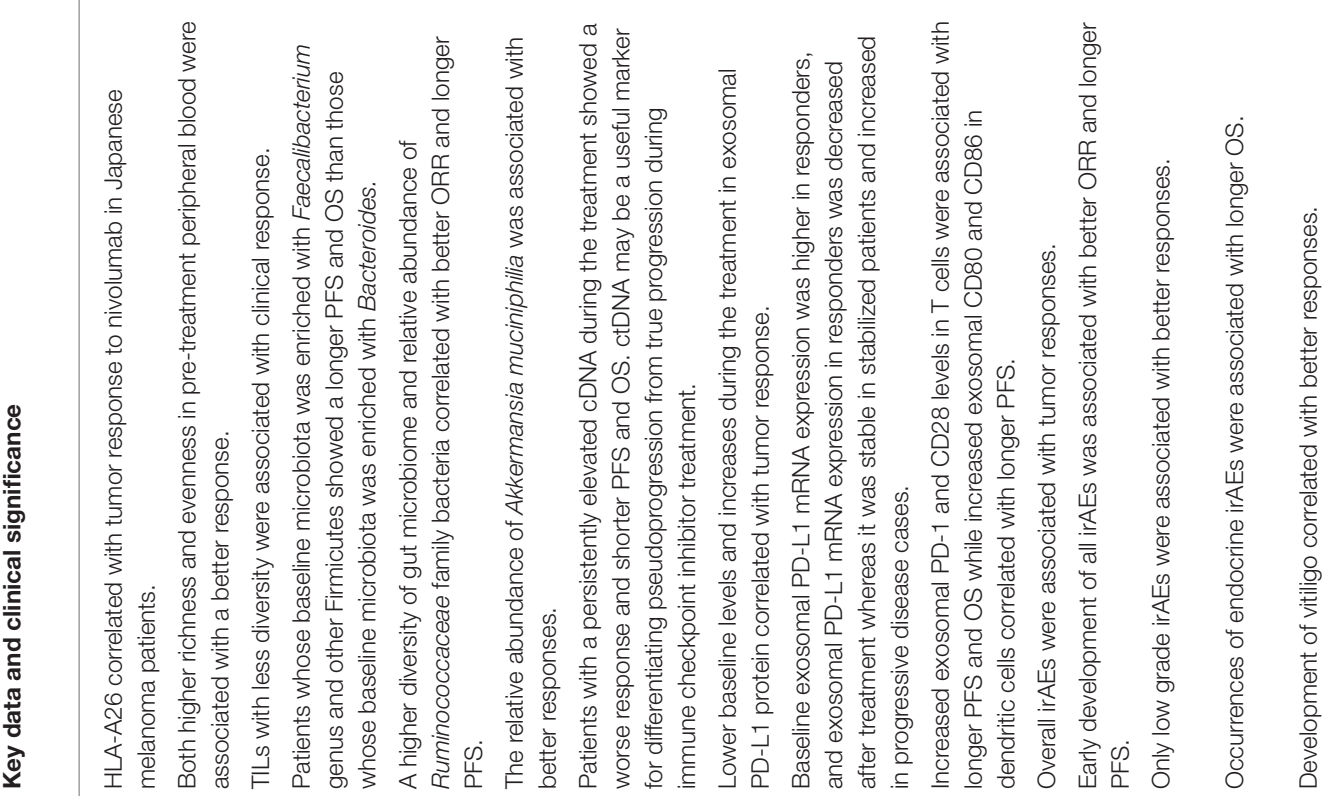
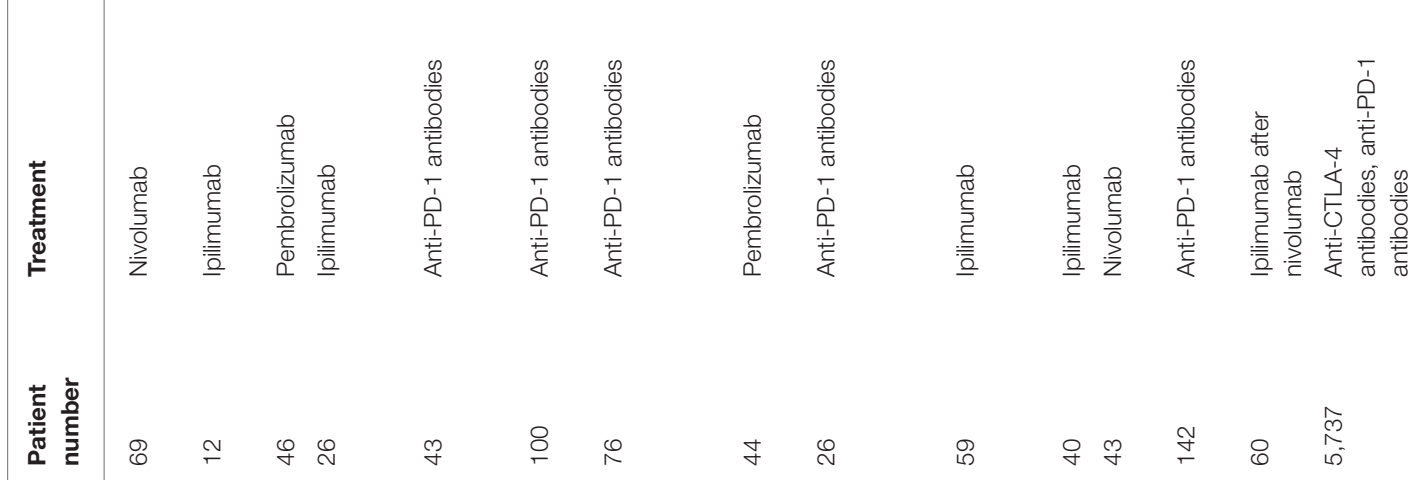

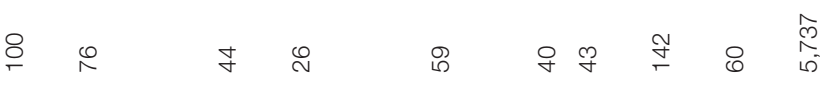
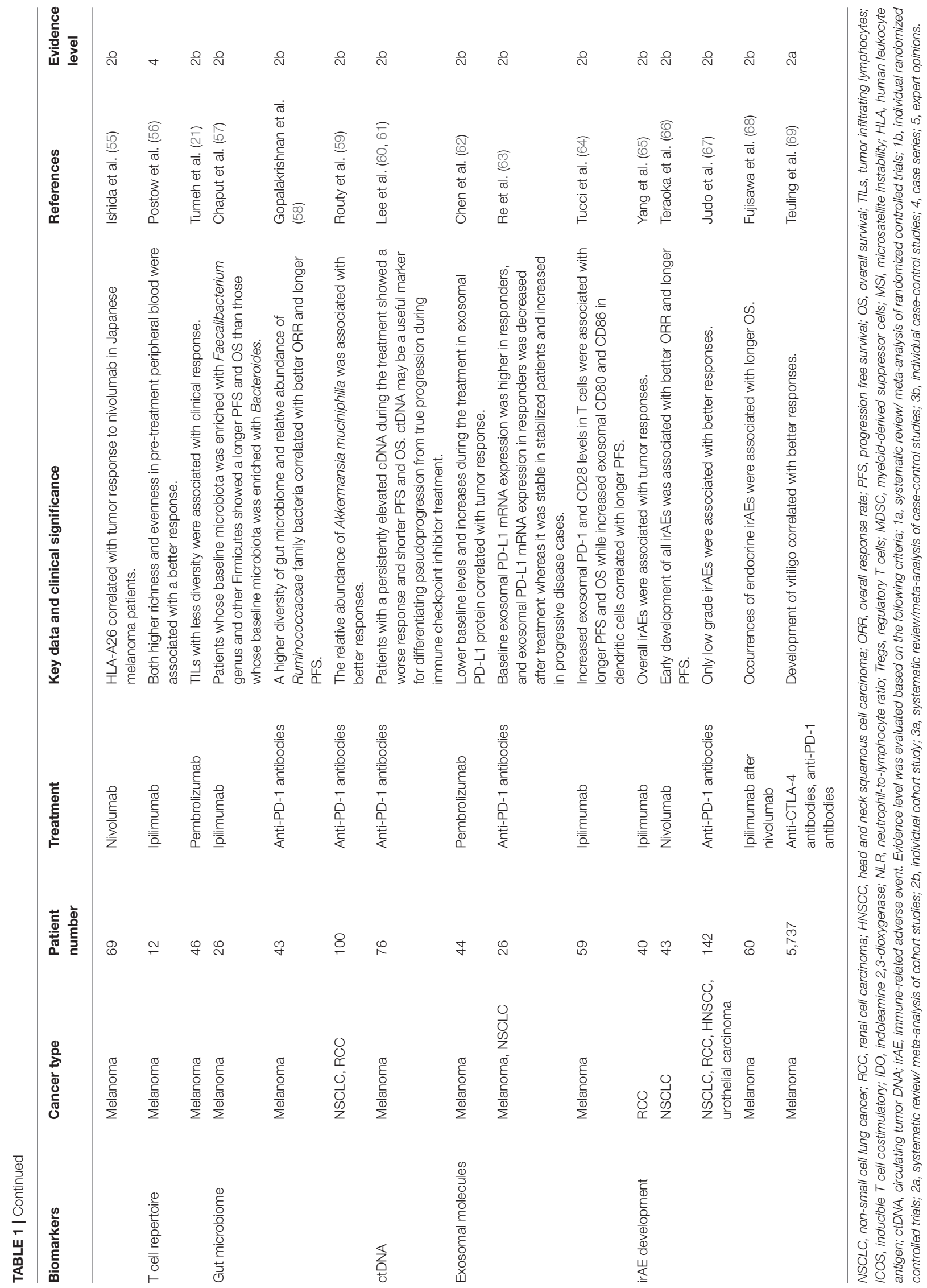
on PD-L1 expression (16). Therefore, PD-L1 expression may be a vital factor to predict tumor response to anti-PD-1 antibodies although tumor responses can be also observed in PD-L1 negative tumors. However, issues remain for accurately assessing PD-L1 expression, including different antibodies used in each study, and the low reproducibility of pathologist evaluations (76). In addition, PD-L1 expression has been reported to vary between primary tumors and metastatic sites (77). Therefore, establishing evaluative standards for tumor PD-L1 expression will enhance its usefulness as a predictive factor.

\section{Inducible T Cell Co-stimulator (ICOS)}

ICOS is a co-stimulating molecule expressed by activated conventional $\mathrm{T}$ cells and regulatory $\mathrm{T}$ cells. A previous report demonstrated that ipilimumab treatment increases expression of ICOS on conventional CD $4^{+} \mathrm{T}$ cells in both blood and tumor tissue in patients with bladder cancer (78). These $\mathrm{CD}^{+} \mathrm{ICOS}^{+}$ $\mathrm{T}$ cells produced IFN $\gamma$ and could recognize tumor antigens (78). In addition, increased expression of ICOS on CD4 ${ }^{+} \mathrm{T}$ cells that is sustained for more than 12 weeks has been reported to correlate with improved survival in melanoma patients treated with ipilimumab (25). Thus, ICOS expression is a potential biomarker for tumor response to ICIs although further studies are needed to establish its utility.

\section{Other Cell Surface Molecules}

Pre-clinical studies using mouse models have indicated that upregulation of alternative inhibitory molecules causes resistance to anti-PD-1 antibody therapy (79). These molecules include TIM-3, LAG-3, and VISTA are therefore suggested to serve as potential target molecules for alternative checkpoint inhibitors. They could also serve as potential biomarkers for ICI response and, indeed, increased TIM-3 expression on circulating $\mathrm{T}$ and NK cells prior to and during treatment has been significantly associated with shorter OS in melanoma patients treated with ipilimumab (26).

\section{Enzymes Related to Immune Response Indoleamine 2,3-dioxygenase (IDO)}

IDO is an enzyme that converts the essential amino acid 1tryptophan into kynurenine and carries an immunosuppressive effect through multiple mechanisms (80). Kynurenine, mediated by IDO, has been shown to induce T cell apoptosis (81), and IDO-induced starvation of tryptophan mediates the conversion of naïve $\mathrm{CD}^{+} \mathrm{T}$ cells into Tregs through GCN2 kinase activation (82). A recent study demonstrated that IDO expression levels in melanoma cells were independently associated with tumor stage (83). IDO has been also reported as a predictor of anti-tumor response by ICIs. Hamid et al showed that baseline IDO expression, as well as baseline FoxP3 expression, in tumor tissue assessed by IHC significantly correlated with better ORR in melanoma patients treated with ipilimumab (27). However, on the contrary, IDO activity as assessed by serum kynurenine/tryptophan ratio has been negatively associated with longer PFS and OS in NSCLC patients treated with nivolumab (28). Therefore, through as-yet unknown mechanisms, IDO activity may serve as a predictive marker for outcomes, which are different dependent on the assessment.

\section{Soluble Isoform of Surface Molecules Soluble CTLA-4 (sCTLA-4)}

Soluble CTLA-4 originates from a spliced variant of an alternative transcript that lacks the transmembrane sequence (84). It can be detected in normal human serum and higher levels of sCTLA-4 have been observed in autoimmune diseases and many types of cancers $(84,85)$. It can bind to CD80/86 on antigen-presenting cells and block the binding of membrane-bound CTLA-4 or CD28 on $\mathrm{T}$ cells, thus avoiding the downregulation of the immune activation cascade $(86,87)$. Pistill et al. demonstrated that higher serum levels of sCTLA-4 (>200 pg/ml) at baseline had both better ORR and OS than lower sCTLA-4 serum levels $(\leq 200 \mathrm{pg} / \mathrm{ml})$ in melanoma patients treated with ipilimumab (29), suggesting that serum sCTLA-4 could be a biomarker for better response to ipilimumab. It is speculated that sCTLA-4 might block the binding of membrane-bound CTLA- 4 to its ligand and thus result in enhanced tumor immunity in synergy with ipilimumab.

\section{Soluble PD-L1 (sPD-L1)}

Soluble PD-L1 may result from alternative variants of the PD-L1 transcripts and cytokine treatment with IFN- $\alpha$, IFN- $\gamma$, or TNF$\alpha$ has been shown to increase secretion of sPD-L1 as well as expression of cell surface PD-L1 in melanoma cell lines (30). It can be detected in blood and elevated levels of circulating sPDL1 have been associated with poor prognoses in many types of cancer (88-90). Consistent with these results, higher levels of baseline sPD-L1 have been significantly associated with worse response and shorter OS in melanoma patients treated with ICIs $(30,31)$. Therefore, baseline sPD-L1 could represent an immune suppressive state and poor response to ICIs although the function of sPD-L1 is not fully understood. In contrast, increases in SPD-1 after treatment with ICIs have been associated with favorable clinical responses (30). Secretion of sPD-1 after ICI treatment may be caused, at least partially, by enhanced production of cytokines such as IFN- $\alpha$, IFN- $\gamma$, or TNF- $\alpha$ due to ICI-mediated anti-tumor response because altered levels of sPD1 after treatment of ipilimumab corresponded to changes in the circulating cytokines (30).

\section{Soluble CD163 (sCD163)}

CD163 is a member of the scavenger receptor family and is mainly expressed by macrophages/monocytes (91). Several reports have shown that $\mathrm{CD} 163^{+} \mathrm{M} 2$ macrophages comprised the main population of the tumor-associated macrophages (TAMs) that play important roles for suppressing anti-tumor immune responses and serum levels of sCD163, generated by proteolytic shedding, is thought to be a marker for TAMs (91, 92). Fujimura et al. reported that serum levels of sCD163 were significantly increased after 6 weeks in responders compared to non-responders after initial treatment with nivolumab for cutaneous melanoma (32). Interestingly, such an increase was not observed in patients with mucosal melanoma although the mechanism for this phenomenon remains unclear. These results 
suggest that sCD163 may serve as a biomarker for patients with specific types of cancer treated with ICIs.

\section{Soluble NKG2D Ligands (sNKG2DLs)}

NKG2D is a member of the C-type lectin-like receptors and is expressed on T, NK, and NKT cells $(93,94)$. The binding of NKG2D with its ligands [MHC class I chain-related gene [MIC] and UL-16-binding protein [ULBP]] elicits activation signals to NK and T cells (93-95). NKG2DLs are usually absent on the surface of normal cells but are induced by various stressors (such as DNA damage) and are often overexpressed by cancer cells $(93,95,96)$. Soluble NKG2DLs, generated as result of proteolytic shedding by tumor cells, can be detected in serum and their levels have been reported to correlate with tumor progression $(94,95,97,98)$. Soluble NKG2DLs suppress antitumor immune responses through multiple mechanisms that include the binding and subsequent endocytosis and degradation of NKG2D on NK and T cells $(97,99,100)$. A multivariate analysis conducted by Maccalli et al. showed that higher levels of circulating sULBP-1, sULBP-2, and LDH at baseline were independent factors of shorter OS in melanoma patients treated with ICIs (33). Interestingly, only LDH, but not sNKG2DLs, significantly correlated with outcomes in patients treated with other therapies, such as chemotherapies and BRAF inhibitors (33), suggesting that soluble circulating sULBP-1 and sULBP2 may be indicators that use of ICIs is more suitable than other therapies.

\section{Cytokines and Chemokines \\ IFN- $\gamma$}

IFN- $\gamma$ is a functionally pleiotropic cytokine that modulates the expression of numerous proteins in exposed cells (101). PDL1 expression is also upregulated mainly controlled by IFN- $\gamma$ (102). IFN- $\gamma$ and its targets play crucial roles in eliminating tumor cells through direct induction of cytotoxic activities as well as enhancing the Th1-related immune response (101). The post-treatment expression levels of IFN- $\gamma$ responsive genes in tumor tissues were associated with better outcomes in patients treated with ipilimumab (34). Similarly, high levels of pretreatment IFN- $\gamma$ expression and its related genes in tumor tissues are associated with longer OS in NSCLC patients treated with durvalumab (35). Similar associations between high expression of IFN- $\gamma$ and CXCL-9, an IFN- $\gamma$ related chemokine, with better ORR was observed in melanoma patients treated with atezolizumab (36). Therefore, high expression of IFN- $\gamma$ and its associated molecules in tumor tissues may be useful biomarkers that are indicative of a better anti-tumor response to ICIs.

\section{TNF- $\alpha$}

TNF- $\alpha$ is an inflammatory cytokine produced by various cells, including immune cells and epithelial cells. It promotes tumor growth and higher serum levels of TNF- $\alpha$ have been reported to be associated with poor prognoses in cancer patients $(103,104)$. Tanaka et al. reported that melanoma patients who showed complete remission, partial remission or long-term stable disease due to nivolumab response had significantly lower serum levels of TNF- $\alpha$ compared to non-responders (37).

\section{IL-6}

IL-6 is produced by a broad variety of cells, including immune cell and tumor cells. It promotes tumor progression via inhibition of cancer cell apoptosis as well as promotion of angiogenesis (105). In a previous study, higher serum IL-6 was associated with shorter OS in melanoma patients treated with IL-2-based immunotherapy (106). Although association of serum IL-6 with response to ICIs has yet to be shown, CRP, whose production is mainly controlled by IL-6 (107), has been reported to be predictive of outcomes in patients treated with ICIs, which bolsters the argument of IL-6 as a potential biomarker of antitumor response during ICI treatment.

\section{Blood Cell Counts Lymphocyte Counts}

Because both CTLA-4 and PD-1 are expressed mainly on lymphocytes, several reports have pointed out the association between blood lymphocyte count and tumor response to ICIs (38-40). Martens et al showed that higher levels of relative lymphocyte counts at baseline were significantly associated with longer OS in melanoma patients treated with ipilimumab (38). In another study, absolute lymphocyte counts after 2 doses of ipilimumab were associated with longer OS in melanoma patients (39). Similarly, Nakamura et al showed that absolute lymphocyte counts at week 3 and 6 after the initial administration of nivolumab significantly correlated with better OS in melanoma patients (40). These results suggest that lymphocyte counts both at baseline and after treatment with ICIs may be useful for predicting better outcomes.

\section{Eosinophil Counts}

Eosinophils also play a crucial role in tumor destruction and recruitment of T cells into the tumor environment (108). Indeed, mice with peripheral blood eosinophilia showed substantial tumor suppression (109). In addition, multiple studies have revealed a positive correlation between increased eosinophil infiltration into tumor tissues and a favorable prognosis in many cancers $(110,111)$. Consistent with this idea, numerous previous studies have reported that higher blood eosinophil counts correlate with favorable outcomes in patients treated with ICIs. Marten et al. demonstrated that in melanoma patients treated with ipilimumab, high absolute, and relative eosinophil counts at baseline were associated with a longer OS (38). Similarly, a multivariate study by Weide et al. demonstrated that relative eosinophil counts at baseline were an independent factor for longer OS and better ORR in melanoma patients treated with pembrolizumab (41). In addition, Gebhardt et al. reported that early increases in absolute eosinophil counts from baseline during ipilimumab treatment were an independent factor for better responses in melanoma patients (42). Therefore, eosinophil counts at both baseline and after ICI treatment may serve as biomarkers for better tumor response.

\section{Neutrophil-to-Lymphocyte Ratio (NLR)}

Fujisawa et al. showed that baseline NLR was associated with poor tumor response in melanoma patients treated with nivolumab (43). Similar findings have also been reported in 
melanoma patients treated with ipilimumab and NSLC patients treated with nivolumab $(41,44)$. In a previously published study, our multivariate analysis revealed that NLR was the only factor associated with both poor ORR and shorter PFS in melanoma patients treated with anti-PD-1 antibodies, suggesting that NLR is a strong predictive factor for poor outcome in patients treated with ICIs (45). Given that lymphocytes play vital roles in the ICI-induced immune response to tumors while neutrophilia represents the response to systemic inflammation (112), a high NLR might represent an impaired specific immune response to tumors. However, increased turnover of tumor cells causes the release of large amounts of damage-associated molecular patterns (DAMPs) from tumor debris, leading to recruitment and activation of neutrophils $(113,114)$. Moreover, numerous reports have also shown that NLR serves as a biomarker for poor response to other treatments, such as chemotherapies and radiation $(115,116)$. Therefore, the NLR might simply represent rapidly expanding tumor cell populations rather than any potential immune response mediated by ICIs.

\section{Tregs}

Tregs, a population characterized by FoxP3 ${ }^{+} \mathrm{CD} 25^{+} \mathrm{CD} 4^{+}$ $\mathrm{T}$ cells, significantly suppress immune responses (117), and it has been shown that their depletion effectively eradicates tumor cells via an enhanced anti-tumor immune response (118, 119). In addition to their immune suppressive function, they may be a target for antibody dependent cellular cytotoxicity (ADCC) by ipilimumab due to their high expression levels of CTLA-4 that make Tregs sentinels for ICI-mediated anti-tumor responses. Indeed, high levels of circulating Tregs at baseline have been associated with longer OS in melanoma patients treated with ipilimumab (38). In addition, decreasing or stable levels of circulating Tregs 12 weeks after initial administration of ipilimumab significantly correlated with better disease control and longer OS than increasing Treg levels. Furthermore, similar results have been obtained in another study, with decreasing levels of circulating Tregs significantly associated with better responses to ipilimumab (46). Therefore, circulating Tregs both at baseline and after treatment with ipilimumab may be useful biomarkers for anti-tumor response.

\section{Myeloid-Derived Suppressor Cells (MDSCs)}

MDSCs are a heterogeneous population of myeloid origin characterized by a failure to differentiate into granulocytes, macrophages or dendritic cells (120). They expand in tumor environments and strongly suppress the activity of immune cells, including $\mathrm{T}$ cells, through a variety of mechanisms such as NO production and arginase-1 overexpression. Both of these processes lead to cell cycle arrest and downregulation of the $\mathrm{T}$ cell receptor (120). MDSCs are defined as $\mathrm{Lin}^{-} \mathrm{CD} 14^{+} \mathrm{HLA}^{-} \mathrm{DR}^{-/ \text {low }}$ (120) and clinical and experimental studies have shown that high infiltration of these cells into tumor tissues are associated with poor prognosis and resistance to therapies $(121,122)$. MDSCs can also be detected in the blood and several studies have demonstrated that the baseline frequency of MDSCs in blood significantly correlates with shorter OS in melanoma patients treated with ipilimumab or nivolumab $(47,48)$. Furthermore, in prostate cancer patients treated with ipilimumab plus a cancer vaccine, the baseline frequency of circulating MDSCs correlated with a shorter OS (49). These results suggest that the frequency of blood MDSCs also serves as a useful biomarker for ICI response.

\section{Serum Markers}

\section{Lactate Dehydrogenase (LDH)}

Generally, baseline serum LDH is an independent factor for poor prognosis in patients with advanced melanoma (123). The same applies to cases of ICI treatment and numerous reports have demonstrated that high baseline LDH was associated with poor anti-tumor response in various cancer patients who received ICI treatment $(50,124,125)$. This poor outcome may simply be caused by increased turnover of tumor cells which enhances LDH release in similar fashion to a high NLR.

\section{CRP}

CRP is produced by hepatocytes and serum levels of it elevate quickly in response to most inflammation (such as bacterial infections). However, CRP does not usually increase during ICI-mediated tumor regression. Simeone et al. reported that a decrease or no change in serum levels of CRP from baseline were significantly associated with longer OS in melanoma patients treated with ipilimumab (46). Therefore, elevated CRP from baseline may indicate inflammation by tumor progression or irAE rather than an antitumor immune response from ICI treatment.

\section{Genomic Mutations Mutation Burden}

Mutation burden, the number of mutations within a tumor genome, is different among and within the cancer types (126). Overall, multiple studies have shown that a high mutation burden was associated with a better response to ICIs $(51,52)$. This mechanism is not fully understood but an increased number of neoantigens (potential tumor-specific $\mathrm{T}$ cell targets) generated by a high mutation burden is thought to cause an enhanced response to ICIs (127). As for melanoma, our study demonstrated that acral lentiginous melanoma (ALM) and mucosal melanoma (MCM), both common types of melanoma in Asians, were less susceptible to immune checkpoint inhibitors than superficial spreading melanoma (SSM) and lentigo maligna melanoma, both major types of Caucasian melanoma (128). This may be explained, at least in part, by the lower mutation burden in ALM and MCM (129). Despite the poor ICI-mediated antitumor response in ALM patients, our retrospective study demonstrated that use of ICIs significantly improved OS in not only SSM but also ALM patients (128).

\section{Microsatellite Instability}

Mutation or silencing of mismatch repair genes, which causes deficient mismatch repair (dMMR), leads to accumulation of multiple mutations and microsatellite instability (MSI). Zhang et al. reported that the immune microenvironment in colorectal cancer differs between dMMR tumors and proficient mismatch 
repair (pMMR) tumors (130). The number of $\mathrm{CD}^{+}$TIL, PD$1^{+}$TIL and $\mathrm{IDO}^{+}$tumor cells was increased in tumors with dMMR compared to those with pMMR, suggesting that $\mathrm{dMMR}$ is indicative of exhausted T-cell-rich environments (130). It has been reported that colon cancer with dMMR frequently shows larger tumors with poorer differentiation (131). In addition, previous studies revealed that patients with dMMR had both a poorer response to conventional chemotherapies and shorter OS than patients with pMMR in many types of cancer $(132,133)$. However, due to the high mutation burden, several clinical trials revealed a high response to anti-PD-1 antibodies in colorectal cancer with dMMR or high levels of MSI (MSI-H) compared to traditional treatments (53), suggesting that dMMR serves as useful indicator for choosing ICIs over other therapies. Recently, a durable response was observed in patients with dMMR or MSI-H across five clinical trials treated with pembrolizmab (KEYNOTE-016, 164, 012, 028, 158). The cancer types included colorectal, endometrial, biliary, gastric, esophageal, pancreatic and breast cancers. Based on these results, the United States Food and Drug Administration approved pembrolizumab for the treatment of any unresetable or metastatic solid tumors that display dMMR or MSI-H. A combination of nivolumab with ipilimumab was also shown to effect a promising response to dMMR/ MSI-H colorectal cancer (134).

\section{Human Leukocyte Antigen (HLA)}

HLA encodes cell surface molecules which present antigenic peptides to the T-cell receptor (TCR) on $\mathrm{T}$ cells. Inoue et al reported that mRNA expression of HLA-A in pre-treatment melanoma was elevated in responders to nivolumab compared to non-responders (54). There are numerous variant alleles at the HLA loci which differ in each individual and Ishida et al reported that HLA-A26, which is relatively common in Japanese but rare in Caucasians, correlated with tumor response to nivolumab in Japanese melanoma patients (55).

\section{T Cell Receptor (TCR) Repertoire}

Since the TCR determines $\mathrm{T}$ cell specificity with respect to tumor cells, the TCR repertoire may be predictive of the ICI-induced anti-tumor immune response. As diversity of the repertoire is increased, the likelihood of a specific immune response to tumor cells is speculated to be elevated (56). A previous study showed that both higher richness and evenness in pre-treatment peripheral blood are associated with a better response to ipilimumab in melanoma patients (56). On the other hand, Tumeh et al. showed that TILs with less diversity were significantly associated with clinical response to pembrolizumab in melanoma patients (21). It is speculated that TILs with less diversity contain a higher proportion of tumor-specific $\mathrm{T}$ cells, and therefore, the anti-tumor response was enhanced by ICIs. In this study, a TIL clone population expanded more than 10 times in responders than non-responders after treatment with pembrolizumab (21), revealing that both diversity and clonal expansion of $\mathrm{T}$ cells may predict ICI response although this indication may differ between blood and tumor tissues.

\section{Gut Microbiome}

Emergent evidence has suggested that the gut microbiome plays crucial roles for the immune response of not only intestinal diseases but also other disorders, including various type of cancers (135). Sivan et al. reported that, in mice, commensal Bifidobacterium enhanced the response to anti-PD-1 antibodies through an augmented dendritic cell function (136). Several studies have also demonstrated that distinct gut microbiota were associated with ICI response in humans. Melanoma patients whose baseline microbiota was enriched with Faecalibacterium genus and other Firmicutes showed a longer PFS and OS than those whose baseline microbiota was enriched with Bacteroides upon ipilimumab treatment (57). In addition, Gopalakrishnan et al. reported that a higher diversity of gut microbiome and relative abundance of Ruminococcaceae family bacteria before starting anti-PD-1 antibodies in melanoma patients correlated with better ORR and longer PFS (58). Moreover, Routy et al. showed that dysbiosis by administration of antibiotics inhibited ICI response in both mice and humans (59). This study also revealed a correlation between clinical responses and the relative abundance of Akkermansia muciniphilia. They also showed that transplantation of Akkermansia muciniphilia into mice enhanced the efficacy of PD-1 antibodies in an IL-12 dependent manner (59). Therefore, gut microbiota may have important implications for the immune response to ICIs.

\section{Liquid Biopsy \\ Circulating Tumor DNA (ctDNA)}

Tumor-derived, fragmented DNA in blood is known as ctDNA, and its precise mechanism of release remains unclear but it has been postulated that it involves a passive release from dying cells and active release from living cells (137-139). It is associated with tumor burden (140), and high levels of ctDNA are an indicator of poor prognoses in patients with various types of cancer (141). Lee et al. demonstrated that melanoma patients with a persistently elevated cDNA during the treatment of anti-PD-1 antibodies show a worse response and shorter PFS and OS (60). In addition, it has been reported that, of nine melanoma patients treated with anti-PD-1 antibodies who showed pseudoprogression (defined as a tumor size increase prior to response often seen in ICI treatment), all patients had a favorable ctDNA profile defined by undetectable ctDNA at baseline or detactable ctDNA at baseline followed by $>10$-fold decreases (61). In contrast, in 20 patients with true progression, all but two had an unfavorable ctDNA profile defined by detectable ctDNA at baseline that remained stable or increased. These results indicate that ctDNA is a useful marker for differentiating pseudoprogression from true progression during ICI treatment.

In addition, the mutation burden of ctDNA has been also assessed and, in line with the correlation of a high mutation burden in tumor tissues, hyper-mutated ctDNA has also been associated with improved OS in patients with diverse cancers who received ICIs (142).

\section{Exosomes}

Exosomes are microvesicles actively released from various cells, including cancer cells, and contain proteins, RNA and DNA 
(63). Exosomes isolated from the plasma of cancer patients contains various immune-related proteins, including PD-1, PDL1, and CTLA-4, with PD-L1 in exosomes showing a suppressive effect on $\mathrm{T}$ cell activities by signaling via $\mathrm{PD}-1$ (62, 143). Similar to the correlation between circulating sPD-L1 and response to ICIs, lower baseline levels, as well as increases, in exosomal PD-L1 protein have been correlated with response to pembrolizumab in melanoma patients (62). However, opposite results were observed in the association of exosomal PD-L1 mRNA expression with response to anti-PD-1 antibodies in patients with melanoma or NSCLS (63). Baseline exosomal PD-L1 mRNA expression was higher in responders compared to non-responders and exosomal PD-L1 mRNA expression in responders was significantly decreased after treatment whereas it was stable in stabilized patients and significantly increased in progressive disease cases (63). Therefore, although the mechanism is unknown, PD-L1 proteins and transcript in the exosome may provide conflicting information on ICI response.

As for other molecules, Tucci et al. recently evaluated the circulating exosomal proteins in $\mathrm{T}$ cells and dendritic cells in melanoma patients treated with ipilimumab (64). They demonstrated that increased exosomal PD-1 and CD28 levels in $\mathrm{T}$ cells were significantly associated with longer PFS and OS while increased exosomal CD80 and CD86 in dendritic cells correlated with longer PFS (64). Such exosomal proteins may reflect potential $\mathrm{T}$ cell/dendritic cell activities and thus lead to predictions of ICI response.

\section{irAE Development}

Since ICIs may cause both irAEs and tumor regression through an augmented immune response, several reports have shown associations between the two events. Overall irAEs have been associated with regression of metastatic renal cell carcinoma or melanoma treated with ipilimumab $(65,144)$. In addition, the presence of overall irAEs was significantly associated with longer OS in melanoma patients treated with nivolumab (145). And moreover, early development of all irAEs has been associated with better ORR and longer PFS in NSCLC patients treated with nivolumab (66). However, other studies failed to show such correlations $(67,68,146)$. A multivariate analysis conducted by Judo et al showed that only low grade irAEs, but not high grade irAEs, are associated with better responses to antiPD-1 antibodies in non-melanoma patients (67). Therefore, only certain irAEs might be associated with tumor regression by ICIs. As for irAEs in each organ, several reports showed correlations between endocrine irAEs and better prognoses. Fujisawa et al. demonstrated that occurrences of endocrine irAEs were associated with longer OS in melanoma patients treated with ipilimumab after nivolumab (68). Similarly, an adjusted analysis by Kim et al. showed that development of thyroid dysfunction was significantly associated with longer PFS and OS in NSCLC patients treated with anti-PD-1 antibodies (147), suggesting that endocrine irAEs may be representative of the potential immune reaction to tumor cells. In a similar fashion, multiple studies showed that development of vitiligo correlated with better responses to ICIs in melanoma patients; this may represent a common immune response against antigens shared by melanocytes and melanomas $(69,148)$. Although ICIs may cause vitiligo in patients with other cancer such as NSCLC and renal cell carcinoma $(149,150)$, associations with outcomes in such cases remain unclear. Several studies showed that skin irAEs, except for vitiligo, were also associated with better outcome in various types of cancer $(145,148)$. However, Fujisawa et al. reported conflicted findings that occurrences of skin irAEs, excluding vitiligo, correlate with a shorter OS in melanoma patients treated with ipilimumab after nivolumab (68). Since skin irAEs include various types of skin disorders, such as prurigolike eruptions, psoriasiform dermatitis and lichenoid reactions, associations with outcomes may be different for each skin irAE.

\section{Biomarkers of irAEs (Table 2)}

The aforementioned irAEs can be induced by all ICIs. However, among the ICIs, both the frequency and the severity are highest in treatment with ipilimumab (161). Severe irAEs (grade $\geq 3$ ) have occurred in $28-56 \%$ and $21-32 \%$ in patients treated with ipilimumab or anti-PD-1/anti-PD-L1 antibodies, respectively $(10,12,16,162,163)$. In the combined treatment of ipilimumab plus nivolumab, much higher rates of severe irAEs are observed $(16,164)$. The organ most affected by irAEs is the skin followed by the gastrointestinal tract, respiratory tract and endocrine organs. A recent meta-analysis revealed that colitis, hypophysitis and rash were more frequent with anti-CTLA-4 antibodies whereas pneumonitis, hypothyroidism, arthralgia, and vitiligo were more common with anti-PD-1 antibodies (165). Most of these irAEs occur within 3-6 months from the initiation of ICI treatment (166-168). Given that most are mild and reversible if they are detected early and properly managed, biomarkers for predicting the occurrence of irAEs are essential. Compared with biomarkers for tumor response, those for irAEs have been less thoroughly investigated and some of the reported biomarkers for irAE overlap with those for tumor responses.

\section{Body Composition Parameters}

Previous reports revealed that sarcopenia was associated with poorer treatment tolerance and increased likelihood of adverse events by various chemotherapies (169, 170). In addition, low muscle attenuation (MA), which refers to increased intramuscular adipose tissue, has been associated with shorter survival in a wide variety of cancers such as melanoma and renal cell carcinoma $(171,172)$. Daly et al evaluated association of these body composition parameters by computer tomography with occurrences of irAEs in melanoma patients treated with ipilimumab. The multivariate analysis in this study showed that both sarcopenia and low MA were independent factors significantly associated with high-grade irAEs (151). Although the exact mechanism is unknown, many studies suggest that sarcopenia and low MA increase susceptibility to systemic inflammation $(173,174)$, and this may play a role in the higher frequency of severe irAEs.

\section{Sex}

Although males have been associated with a more favorable response to ICIs, a study in melanoma patients treated with ipilimumab by Valpione et al reported that females 


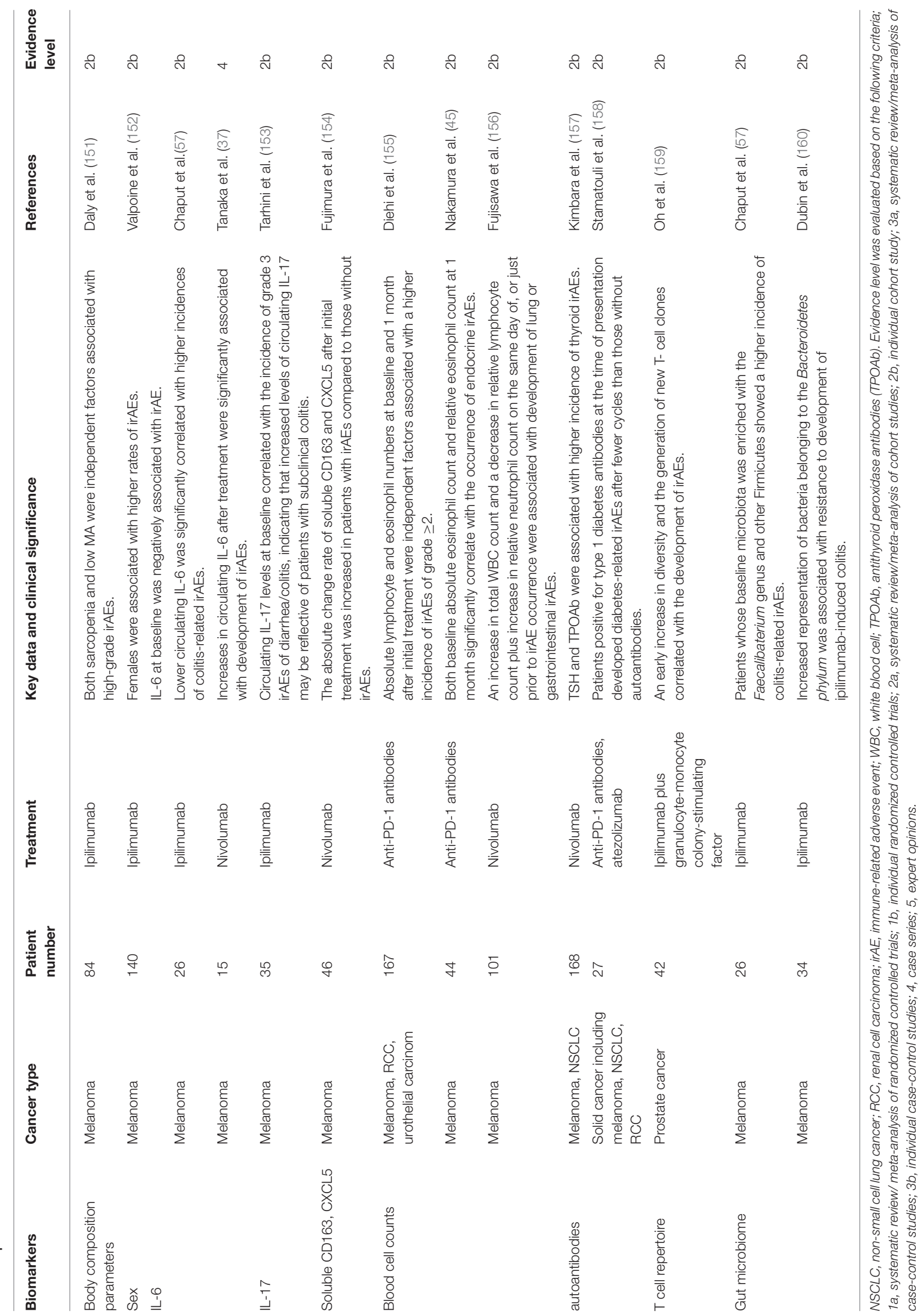


were associated with higher rates of irAEs (152). Sexspecific factors, including hormones, play important roles in the immune response, and it is well-known that females are at a higher risk of several autoimmune diseases (175). Therefore, immune reactions to self-tissues mediated by female-specific factors may lead to an increased likelihood of irAEs.

\section{Serum Factors IL-6}

Similar to the correlation with poor tumor response, it has been reported that circulating IL-6 at baseline was negatively associated with irAE occurrence in melanoma patients treated with ipilimumab (152). Another study showed that lower circulating IL-6, as well as IL-8, was significantly correlated with higher incidences of colitis-related irAEs (57). This may be explained by the immunosuppressive effects of IL-6 in certain conditions, including the induction of MDSC (176178). In contrast, Tanaka et al. assessed the fluctuation of multiple cytokines in melanoma patients treated with nivolumab and showed that increases in circulating IL-6 after treatment were significantly associated with development of irAEs (37). These results indicate that both lower baseline IL-6 and increase after ICI treatment may serve as predictive markers for irAE occurrence.

\section{IL-17}

IL-17 is a cytokine with a variety of inflammatory effects, including the recruitment of neutrophils, and it is wellknown that circulating IL-17 levels are increased in patients with inflammatory bowel disease (179). Tarhini et al. assessed candidate circulating factors which were associated with irAEs in melanoma patients treated with ipilimumab as a neoadjuvant therapy and revealed that circulating IL-17 levels at baseline significantly correlated with the incidence of grade 3 irAEs of diarrhea/colitis (153). This indicates that increased levels of circulating IL-17 may be reflective of patients with subclinical colitis, the development of which would be normally inhibited by CTLA- 4 .

\section{Soluble CD163 (sCD163) and CXCL5}

Circulating levels of sCD163, which is derived from macrophages, increase in various autoimmune disorders, including rheumatoid arthritis and pemphigus vulgaris, and are reflective of their activities $(176,180)$. CXCL5 is a chemokine which can attract CXCR2 ${ }^{+}$myeloid cells and can be produced by $\mathrm{CD}_{163}{ }^{+}$macrophages. It is also known to be a biomarker for several autoimmune disorders $(176,181)$. Fujimura et al evaluated circulating SCD163 and CXCL5 levels at baseline and day 42 after initial treatment with nivolumab in melanoma patients (154), showing that the sCD163 absolute change rate was significantly increased in patients with irAEs compared to those without irAEs. Although there were no significant differences, the absolute change rate of CXCL5 also tended to be higher in patients with irAEs, suggesting that absolute changes within sCD163 and CXCL5 levels after ICI treatment could serve as possible biomarkers for irAE development.

\section{Blood Cells}

Since both $\mathrm{T}$ cells and eosinophils are crucial for cellular immunity, blood cell counts of these cells may also be correlated with irAE development. A multivariate analysis conducted by Diehi et al. demonstrated that, in solid tumor patients (including melanoma, renal cell carcinoma, and urothelial carcinoma) treated with anti-PD-1 antibodies, absolute lymphocyte and eosinophil numbers at baseline and 1 month after initial treatment were independent factors that were significantly associated with a higher incidence of irAEs of grade $\geq 2$ (155). In addition, our study demonstrated that both baseline absolute eosinophil count and relative eosinophil count at 1 month significantly correlate with the occurrence of endocrine irAEs in melanoma patients treated with anti-PD-1 antibodies (45). Therefore, circulating lymphocyte and eosinophil numbers may predict not only tumor responses but also the occurrence of ICI-mediated irAEs.

In contrast, Fujisawa et al. investigated fluctuations in blood cell count on the same day of, or just prior to irAE occurrence, in melanoma patients treated with nivolumab (156). Univariate analyses revealed that increases in total white blood cell (WBC) count and decreases in relative lymphocyte count from baseline were associated with severe irAEs of grade $\geq 3$ although multivariate analyses failed to show independence. They also analyzed the correlation with irAEs of each organ and found that the same factors, namely an increase in total WBC count and a decrease in relative lymphocyte count plus increase in relative neutrophil count, were significantly associated with development of lung or gastrointestinal irAEs. This could be caused by neutrophil-dominant infiltration into the affected organs since DAMPs from severely damaged cells promote neutrophil recruitment (182). Indeed, active colitis in patients treated with ipilimumab saw severe neutrophil infiltration into the lamina propria (183), indicating that these factors may be useful for predicting irAEs that are currently developing or may soon develop.

\section{Autoantibodies}

Detection of autoantibodies is speculated to predict development of irAEs related to the autoantibodies (184). Kimbara et al. assessed TSH, free T3, free T4, antithyroid peroxidase antibodies (TPOAb) and antithyroglobulin antibodies at baseline in patients with solid tumors treated with nivolumab and multivariate analyses revealed that TSH and TPOAb were significantly associated with higher incidence of thyroid irAEs (157). Stamatouli et al. measured diabetes autoantibodies (glutamic and decarboxylase 65 antibodies, islet antigen 2 antibodies, and insulin autoantibodies) in solid cancer patients treated with anti-PD-1 or anti-PDL1 antibodies, and found that patients positive for type 1 diabetes antibodies at the time of presentation developed diabetes-related irAEs after fewer cycles than those without autoantibodies (158). They also measured autoantibodies prior to treatment in three patients, and one was already positive, 
indicating that autoantibodies may be useful to predict their related irAEs.

\section{T Cell Repertoire}

The $\mathrm{T}$ cell repertoire has been reported to correlate with irAEs as well as tumor response. Oh et al assessed the repertoire of circulating $\mathrm{T}$ cells in patients with metastatic castration-resistant prostate cancer treated with a combination of ipilimumab and granulocyte-monocyte colony-stimulating factor (159). They found that initial broadening in the repertoire occurred within 2 weeks of treatment, which significantly preceded irAEs onset, and an early increase in diversity and the generation of new clones were correlated with the development of irAEs. These results suggest that increased $\mathrm{T}$ cell diversity in response to ICI treatment could be a sign of immune response to normal tissues as well as tumor tissues.

\section{Gut Microbiome}

It is suggested that inflammatory bowel diseases (IBD) may result from a loss of tolerance to commensal bacteria and dysbiosis is a well-known factor that is significantly involved in the pathogenesis of IBD (185). Gut microbiota have been also reported as predictive of colitis-related irAEs. Melanoma patients treated with ipilimumab whose baseline microbiota was enriched with the Faecalibaterium genus and other Firmicutes showed a higher incidence of colitis-related irAEs although they were also associated with better outcomes (57). In contrast, this study showed no occurrences of colitis irAEs in any patients with Bacteroidetes (57). Similarly, Dubin et al. demonstrated that increased representation of bacteria belonging to the Bacteroidetes phylum was associated with resistance to development of ipilimumab-induced colitis (160).

\section{REFERENCES}

1. Madorsky Rowdo FP, Baron A, Urrutia M, Mordoh J. Immunotherapy in cancer: a combat between tumors and the immune system; you win some, you lose some. Front Immunol. (2015) 6:127. doi: 10.3389/fimmu.2015.00127

2. Romano E, Kusio-Kobialka M, Foukas PG, Baumgaertner P, Meyer C, Ballabeni $\mathrm{P}$, et al. Ipilimumab-dependent cell-mediated cytotoxicity of regulatory $\mathrm{T}$ cells ex vivo by nonclassical monocytes in melanoma patients. Proc Natl Acad Sci USA. (2015) 112:6140-5. doi: 10.1073/pnas.1417320112

3. Cho J, Ahn S, Yoo KH, Kim JH, Choi SH, Jang KT, et al. Treatment outcome of PD-1 immune checkpoint inhibitor in Asian metastatic melanoma patients: correlative analysis with PD-L1 immunohistochemistry. Invest New Drugs. (2016) 34:677-84. doi: 10.1007/s10637-016-0373-4

4. Robert C, Long GV, Brady B, Dutriaux C, Maio M, Mortier L, et al. Nivolumab in previously untreated melanoma without BRAF mutation. $N$ Engl J Med. (2015) 372:320-30. doi: 10.1056/NEJMoa1412082

5. Robert C, Schachter J, Long GV, Arance A, Grob JJ, Mortier L, et al. Pembrolizumab versus ipilimumab in advanced melanoma. $N$ Engl J Med. (2015) 372:2521-32. doi: 10.1056/NEJMoa1503093

6. Hodi FS, O’Day SJ, McDermott DF, Weber RW, Sosman JA, Haanen JB, et al. Improved survival with ipilimumab in patients with metastatic melanoma. $N$ Engl J Med. (2010) 363:711-23. doi: 10.1056/NEJMoa1003466

7. Mazza C, Escudier B, Albiges L. Nivolumab in renal cell carcinoma: latest evidence and clinical potential. Ther Adv Med Oncol. (2017) 9:17181. doi: $10.1177 / 1758834016679942$

\section{Tumor Type}

A recent meta-analysis demonstrated that the frequency of each type of irAE depends on cancer type (165). Melanoma patients had a higher frequency of skin and gastrointestinal irAEs but a lower frequency of pneumonia compared with NSCLC patients (165). In addition, dermatitis, arthritis and myalgia were more frequent in melanoma patients than in renal cell carcinoma patients whereas pneumonitis and dyspnea were found to be less common in melanoma cases (165). Although the precise mechanism remains unclear, induced immune responses to antigens of normal tissue shared with or cross-reactive with those of each cancer may be an explanation.

\section{CONCLUSION}

Although numerous predictive biomarkers for tumor response and irAEs during ICI treatment have been identified, there are no absolutely predictive biomarkers as yet. Therefore, multiple biomarkers should be taken into consideration in choosing or quitting ICI treatments. Because immune reactions induced by ICIs are quite complex and many factors are involved, identifying new biomarkers will provide mechanistic insights into the ways how ICIs modulate the anti-tumor response and irAEs in specific patients, as well as lead to the development of novel treatments to target the identified biomarkers.

\section{AUTHOR CONTRIBUTIONS}

The author confirms being the sole contributor of this work and has approved it for publication.
8. Kim BJ, Kim JH, Kim HS. Survival benefit of immune checkpoint inhibitors according to the histology in non-small-cell lung cancer: a meta-analysis and review. Oncotarget. (2017) 8:51779-85. doi: 10.18632/oncotarget.17213

9. Fehrenbacher L, Spira A, Ballinger M, Kowanetz M, Vansteenkiste J, Mazieres J, et al. Atezolizumab versus docetaxel for patients with previously treated non-small-cell lung cancer (POPLAR): a multicentre, openlabel, phase 2 randomised controlled trial. Lancet. (2016) 387:1837-46. doi: 10.1016/s0140-6736(16) 00587-0

10. Weber J, Mandala M, Del Vecchio M, Gogas HJ, Arance AM, Cowey CL, et al. Adjuvant nivolumab versus ipilimumab in resected stage III or IV melanoma. NEngl J Med. (2017) 377:1824-35. doi: 10.1056/NEJMoa1709030

11. van Zeijl MC, van den Eertwegh AJ, Haanen JB, Wouters MW. (Neo) adjuvant systemic therapy for melanoma. Eur J Surg Oncol. (2017) 43:53443. doi: 10.1016/j.ejso.2016.07.001

12. Eggermont AMM, Blank CU, Mandala M, Long GV, Atkinson V, Dalle S, et al. Adjuvant pembrolizumab versus placebo in resected stage III melanoma. $N$ Engl J Med. (2018) 378:1789-801. doi: 10.1056/NEJMoa1802357

13. Amaria RN, Reddy SM, Tawbi HA, Davies MA, Ross MI, Glitza IC, et al. Neoadjuvant immune checkpoint blockade in high-risk resectable melanoma. Nat Med. (2018) 24:1649-54. doi: 10.1038/s41591-018-0197-1

14. Keung EZ, Lazar AJ, Torres KE, Wang WL, Cormier JN, Ashleigh Guadagnolo B, et al. Phase II study of neoadjuvant checkpoint blockade in patients with surgically resectable undifferentiated pleomorphic sarcoma and dedifferentiated liposarcoma. BMC Cancer. (2018) 18:913. doi: 10.1186/s12885-018-4829-0 
15. Yeh J, Marrone KA, Forde PM. Neoadjuvant and consolidation immunooncology therapy in stage III non-small cell lung cancer. J Thorac Dis. (2018) 10:S451-S9. doi: 10.21037/jtd.2018.01.109

16. Wolchok JD, Chiarion-Sileni V, Gonzalez R, Rutkowski P, Grob JJ, Cowey CL, et al. Overall survival with combined nivolumab and ipilimumab in advanced melanoma. N Engl J Med. (2017) 377:1345-56. doi: 10.1056/NEJMoa1709684

17. Wu Y, Ju Q, Jia K, Yu J, Shi H, Wu H, et al. Correlation between sex and efficacy of immune checkpoint inhibitors (PD-1 and CTLA-4 inhibitors). Int J Cancer. (2018) 143:45-51. doi: 10.1002/ijc.31301

18. Nosrati A, Tsai KK, Goldinger SM, Tumeh P, Grimes B, Loo K, et al. Evaluation of clinicopathological factors in $\mathrm{PD}-1$ response: derivation and validation of a prediction scale for response to PD-1 monotherapy. $\mathrm{Br} J$ Cancer. (2017) 116:1141-7. doi: 10.1038/bjc.2017.70

19. Nishijima TF, Muss HB, Shachar SS, Moschos SJ. Comparison of efficacy of immune checkpoint inhibitors (ICIs) between younger and older patients: a systematic review and meta-analysis. Cancer Treat Rev. (2016) 45:307. doi: 10.1016/j.ctrv.2016.02.006

20. Joseph RW, Elassaiss-Schaap J, Kefford R, Hwu WJ, Wolchok JD, Joshua $\mathrm{AM}$, et al. Baseline tumor size is an independent prognostic factor for overall survival in patients with melanoma treated with pembrolizumab. Clin Cancer Res. (2018) 24:4960-7. doi: 10.1158/1078-0432.Ccr-17-2386

21. Tumeh PC, Harview CL, Yearley JH, Shintaku IP, Taylor EJ, Robert L, et al. PD-1 blockade induces responses by inhibiting adaptive immune resistance. Nature. (2014) 515:568-71. doi: 10.1038/nature13954

22. Weber JS, D’Angelo SP, Minor D, Hodi FS, Gutzmer R, Neyns B, et al. Nivolumab versus chemotherapy in patients with advanced melanoma who progressed after anti-CTLA-4 treatment (CheckMate 037): a randomised, controlled, open-label, phase 3 trial. Lancet Oncol. (2015) 16:375-84. doi: 10.1016/S1470-2045(15) 70076-8

23. Daud AI, Wolchok JD, Robert C, Hwu WJ, Weber JS, Ribas A, et al. Programmed death-ligand 1 expression and response to the antiprogrammed death 1 antibody pembrolizumab in melanoma. J Clin Oncol. (2016) 34:4102-9. doi: 10.1200/JCO.2016.67.2477

24. Gandhi L, Rodriguez-Abreu D, Gadgeel S, Esteban E, Felip E, De Angelis F, et al. Pembrolizumab plus chemotherapy in metastatic non-small-cell lung cancer. N Engl J Med. (2018) 378:2078-92. doi: 10.1056/NEJMoa18 01005

25. Carthon BC, Wolchok JD, Yuan J, Kamat A, Ng Tang DS, Sun J, et al. Preoperative CTLA-4 blockade: tolerability and immune monitoring in the setting of a presurgical clinical trial. Clin Cancer Res. (2010) 16:286171. doi: 10.1158/1078-0432.CCR-10-0569

26. Tallerico R, Cristiani CM, Staaf E, Garofalo C, Sottile R, Capone M, et al. IL-15, TIM-3 and NK cells subsets predict responsiveness to anti-CTLA-4 treatment in melanoma patients. Oncoimmunology. (2017) 6:e1261242. doi: 10.1080/2162402X.2016.1261242

27. Hamid O, Schmidt H, Nissan A, Ridolfi L, Aamdal S, Hansson J, et al. A prospective phase II trial exploring the association between tumor microenvironment biomarkers and clinical activity of ipilimumab in advanced melanoma. J Transl Med. (2011) 9:204. doi: 10.1186/1479-5876-9-204

28. Botticelli A, Cerbelli B, Lionetto L, Zizzari I, Salati M, Pisano A, et al. Can IDO activity predict primary resistance to anti-PD-1 treatment in NSCLC? J Transl Med. (2018) 16:219. doi: 10.1186/s12967-018-1595-3

29. Pistillo MP, Fontana V, Morabito A, Dozin B, Laurent S, Carosio $\mathrm{R}$, et al. Soluble CTLA-4 as a favorable predictive biomarker in metastatic melanoma patients treated with ipilimumab: an Italian melanoma intergroup study. Cancer Immunol Immunother. (2019) 68:97-107. doi: 10.1007/s00262-018-2258-1

30. Zhou J, Mahoney KM, Giobbie-Hurder A, Zhao F, Lee S, Liao $\mathrm{X}$, et al. Soluble PD-L1 as a biomarker in malignant melanoma treated with checkpoint blockade. Cancer Immunol Res. (2017) 5:480-92. doi: 10.1158/2326-6066.CIR-16-0329

31. Okuma Y, Wakui H, Utsumi H, Sagawa Y, Hosomi Y, Kuwano K, et al. Soluble programmed cell death ligand 1 as a novel biomarker for nivolumab therapy for non-small-cell lung cancer. Clin Lung Cancer. (2018) 19:410-7 e1. doi: 10.1016/j.cllc.2018.04.014

32. Fujimura T, Sato Y, Tanita K, Kambayashi Y, Otsuka A, Fujisawa Y, et al. Serum level of soluble CD163 may be a predictive marker of the effectiveness of nivolumab in patients with advanced cutaneous melanoma. Front Oncol. (2018) 8:530. doi: 10.3389/fonc.2018.00530

33. Maccalli C, Giannarelli D, Chiarucci C, Cutaia O, Giacobini G, Hendrickx W, et al. Soluble NKG2D ligands are biomarkers associated with the clinical outcome to immune checkpoint blockade therapy of metastatic melanoma patients. Oncoimmunology. (2017) 6:e1323618. doi: 10.1080/2162402X.2017.13 23618

34. Ji RR, Chasalow SD, Wang L, Hamid O, Schmidt H, Cogswell J, et al. An immune-active tumor microenvironment favors clinical response to ipilimumab. Cancer Immunol Immunother. (2012) 61:1019-31. doi: 10.1007/s00262-011-1172-6

35. Higgs BW, Morehouse CA, Streicher K, Brohawn PZ, Pilataxi F, Gupta $\mathrm{A}$, et al. Interferon gamma messenger RNA signature in tumor biopsies predicts outcomes in patients with non-small cell lung carcinoma or urothelial cancer treated with durvalumab. Clin Cancer Res. (2018) 24:385766. doi: 10.1158/1078-0432.Ccr-17-3451

36. Herbst RS, Soria JC, Kowanetz M, Fine GD, Hamid O, Gordon MS, et al. Predictive correlates of response to the anti-PD-L1 antibody MPDL3280A in cancer patients. Nature. (2014) 515:563-7. doi: 10.1038/nature 14011

37. Tanaka R, Okiyama N, Okune M, Ishitsuka Y, Watanabe R, Furuta $\mathrm{J}$, et al. Serum level of interleukin-6 is increased in nivolumabassociated psoriasiform dermatitis and tumor necrosis factor-alpha is a biomarker of nivolumab recativity. J Dermatol Sci. (2017) 86:713. doi: 10.1016/j.jdermsci.2016.12.019

38. Martens A, Wistuba-Hamprecht K, Geukes Foppen M, Yuan J, Postow MA, Wong $\mathrm{P}$, et al. Baseline peripheral blood biomarkers associated with clinical outcome of advanced melanoma patients treated with ipilimumab. Clin Cancer Res. (2016) 22:2908-18. doi: 10.1158/1078-0432.Ccr-15-2412

39. Wilgenhof S, Du Four S, Vandenbroucke F, Everaert H, Salmon I, Lienard $D$, et al. Single-center experience with ipilimumab in an expanded access program for patients with pretreated advanced melanoma. J Immunother. (2013) 36:215-22. doi: 10.1097/CJI.0b013e31828eed39

40. Nakamura Y, Kitano S, Takahashi A, Tsutsumida A, Namikawa K, Tanese K, et al. Nivolumab for advanced melanoma: pretreatment prognostic factors and early outcome markers during therapy. Oncotarget. (2016) 7:7740415. doi: 10.18632/oncotarget.12677

41. Weide B, Martens A, Hassel JC, Berking C, Postow MA, Bisschop $\mathrm{K}$, et al. Baseline biomarkers for outcome of melanoma patients treated with pembrolizumab. Clin Cancer Res. (2016) 22:5487-96. doi: 10.1158/1078-0432.Ccr-16-0127

42. Gebhardt C, Sevko A, Jiang H, Lichtenberger R, Reith M, Tarnanidis K, et al. Myeloid cells and related chronic inflammatory factors as novel predictive markers in melanoma treatment with ipilimumab. Clin Cancer Res. (2015) 21:5453-9. doi: 10.1158/1078-0432.Ccr-15-0676

43. Fujisawa Y, Yoshino K, Otsuka A, Funakoshi T, Fujimura T, Yamamoto Y, et al. Baseline neutrophil to lymphocyte ratio combined with serum lactate dehydrogenase level associated with outcome of nivolumab immunotherapy in a Japanese advanced melanoma population. Br J Dermatol. (2018) 179:213-5. doi: 10.1111/bjd.16427

44. Bagley SJ, Kothari S, Aggarwal C, Bauml JM, Alley EW, Evans TL, et al. Pretreatment neutrophil-to-lymphocyte ratio as a marker of outcomes in nivolumab-treated patients with advanced non-small-cell lung cancer. Lung Cancer. (2017) 106:1-7. doi: 10.1016/j.lungcan.2017.01.013

45. Nakamura Y, Tanaka R, Maruyama H, Ishitsuka Y, Okiyama N, Watanabe $\mathrm{R}$, et al. Correlation between blood cell count and outcome of melanoma patients treated with anti-PD-1 antibodies. Jpn J Clin Oncol. (2019) 2019:201. doi: 10.1093/jjco/hyy201

46. Simeone E, Gentilcore G, Giannarelli D, Grimaldi AM, Caraco C, Curvietto $\mathrm{M}$, et al. Immunological and biological changes during ipilimumab treatment and their potential correlation with clinical response and survival in patients with advanced melanoma. Cancer Immunol Immunother. (2014) 63:67583. doi: $10.1007 / \mathrm{s} 00262-014-1545-8$

47. Weber J, Gibney G, Kudchadkar R, Yu B, Cheng P, Martinez AJ, et al. Phase I/II study of metastatic melanoma patients treated with nivolumab who had progressed after ipilimumab. Cancer Immunol Res. (2016) 4:34553. doi: 10.1158/2326-6066.Cir-15-0193 
48. Kitano S, Postow MA, Ziegler CG, Kuk D, Panageas KS, Cortez C, et al. Computational algorithm-driven evaluation of monocytic myeloidderived suppressor cell frequency for prediction of clinical outcomes. Cancer Immunol Res. (2014) 2:812-21. doi: 10.1158/2326-6066.Cir-14-0013

49. Santegoets SJ, Stam AG, Lougheed SM, Gall H, Jooss K, Sacks $\mathrm{N}$, et al. Myeloid derived suppressor and dendritic cell subsets are related to clinical outcome in prostate cancer patients treated with prostate GVAX and ipilimumab. J Immunother Cancer. (2014) 2:31. doi: 10.1186/s40425-014-0031-3

50. Delyon J, Mateus C, Lefeuvre D, Lanoy E, Zitvogel L, Chaput N, et al. Experience in daily practice with ipilimumab for the treatment of patients with metastatic melanoma: an early increase in lymphocyte and eosinophil counts is associated with improved survival. Ann Oncol. (2013) 24:1697703. doi: 10.1093/annonc/mdt027

51. Snyder A, Makarov V, Merghoub T, Yuan J, Zaretsky JM, Desrichard A, et al. Genetic basis for clinical response to CTLA-4 blockade in melanoma. N Engl J Med. (2014) 371:2189-99. doi: 10.1056/NEJMoa1406498

52. Van Allen EM, Miao D, Schilling B, Shukla SA, Blank C, et al. Genomic correlates of response to CTLA-4 blockade in metastatic melanoma. Science. (2015) 350:207-11. doi: 10.1126/science.aad0095

53. Overman MJ, McDermott R, Leach JL, Lonardi S, Lenz HJ, Morse MA, et al. Nivolumab in patients with metastatic DNA mismatch repair-deficient or microsatellite instability-high colorectal cancer (CheckMate 142): an open-label, multicentre, phase 2 study. Lancet Oncol. (2017) 18:1182-91. doi: 10.1016/s1470-2045(17)30422-9

54. Inoue $\mathrm{H}$, Park JH, Kiyotani $\mathrm{K}$, Zewde $\mathrm{M}$, Miyashita A, Jinnin $\mathrm{M}$, et al. Intratumoral expression levels of PD-L1, GZMA, and HLAA along with oligoclonal $\mathrm{T}$ cell expansion associate with response to nivolumab in metastatic melanoma. Oncoimmunology. (2016) 5:e1204507. doi: 10.1080/2162402x.2016.1204507

55. Ishida Y, Otsuka A, Tanaka H, Levesque MP, Dummer R, Kabashima K. HLA-A*26 is correlated with response to nivolumab in japanese melanoma patients. J Invest Dermatol. (2017) 137:2443-4. doi: 10.1016/j.jid.2017. 06.023

56. Postow MA, Manuel M, Wong P, Yuan J, Dong Z, Liu C, et al. Peripheral $\mathrm{T}$ cell receptor diversity is associated with clinical outcomes following ipilimumab treatment in metastatic melanoma. Jimmunother Cancer. (2015) 3:23. doi: 10.1186/s40425-015-0070-4

57. Chaput N, Lepage P, Coutzac C, Soularue E, Le Roux K, Monot C, et al. Baseline gut microbiota predicts clinical response and colitis in metastatic melanoma patients treated with ipilimumab. Ann Oncol. (2017) 28:136879. doi: 10.1093/annonc/mdx108

58. Gopalakrishnan V, Spencer CN, Nezi L, Reuben A, Andrews MC, Karpinets TV, et al. Gut microbiome modulates response to antiPD-1 immunotherapy in melanoma patients. Science. (2018) 359:97103. doi: $10.1126 /$ science.aan4236

59. Routy B, Le Chatelier E, Derosa L, Duong CPM, Alou MT, Daillere R, et al. Gut microbiome influences efficacy of PD-1-based immunotherapy against epithelial tumors. Science. (2018) 359:91-7. doi: 10.1126/science.aan3706

60. Lee JH, Long GV, Boyd S, Lo S, Menzies AM, Tembe V, et al. Circulating tumour DNA predicts response to anti-PD1 antibodies in metastatic melanoma. Ann Oncol. (2017) 28:1130-6. doi: 10.1093/annonc/mdx026

61. Lee JH, Long GV, Menzies AM, Lo S, Guminski A, Whitbourne $\mathrm{K}$, et al. Association between circulating tumor DNA and pseudoprogression in patients with metastatic melanoma treated with anti-programmed cell death 1 antibodies. JAMA Oncol. (2018) 4:717-21. doi: 10.1001/jamaoncol.2017.5332

62. Chen G, Huang AC, Zhang W, Zhang G, Wu M, Xu W, et al. Exosomal $\mathrm{PD}-\mathrm{L} 1$ contributes to immunosuppression and is associated with anti-PD-1 response. Nature. (2018) 560:382-6. doi: 10.1038/s41586-018-0392-8

63. Del Re M, Marconcini R, Pasquini G, Rofi E, Vivaldi C, Bloise F, et al. PD-L1 mRNA expression in plasma-derived exosomes is associated with response to anti-PD-1 antibodies in melanoma and NSCLC. $\mathrm{Br} J$ Cancer. (2018) 118:820-4. doi: 10.1038/bjc.2018.9

64. Tucci M, Passarelli A, Mannavola F, Stucci LS, Ascierto PA, Capone $\mathrm{M}$, et al. Serum exosomes as predictors of clinical response to ipilimumab in metastatic melanoma. Oncoimmunology. (2018) 7:e1387706. doi: 10.1080/2162402X.2017.1387706
65. Yang JC, Hughes M, Kammula U, Royal R, Sherry RM, Topalian SL, et al. Ipilimumab (anti-CTLA4 antibody) causes regression of metastatic renal cell cancer associated with enteritis and hypophysitis. J Immunother. (2007) 30:825-30. doi: 10.1097/CJI.0b013e318156e47e

66. Teraoka S, Fujimoto D, Morimoto T, Kawachi H, Ito M, Sato Y, et al. Early immune-related adverse events and association with outcome in advanced non-small cell lung cancer patients treated with nivolumab: a prospective cohort study. J Thorac Oncol. (2017) 12:1798-805. doi: 10.1016/j.jtho.2017.08.022

67. Judd J, Zibelman M, Handorf E, O’Neill J, Ramamurthy C, Bentota S, et al. Immune-related adverse events as a biomarker in non-melanoma patients treated with programmed cell death 1 inhibitors. Oncologist. (2017) 22:1232-7. doi: 10.1634/theoncologist.2017-0133

68. Fujisawa Y, Yoshino K, Otsuka A, Funakoshi T, Uchi H, Fujimura T, et al. Retrospective study of advanced melanoma patients treated with ipilimumab after nivolumab: analysis of 60 Japanese patients. J Dermatol Sci. (2018) 89:60-6. doi: 10.1016/j.jdermsci.2017.10.009

69. Teulings HE, Limpens J, Jansen SN, Zwinderman AH, Reitsma JB, Spuls PI, et al. Vitiligo-like depigmentation in patients with stage IIIIV melanoma receiving immunotherapy and its association with survival: a systematic review and meta-analysis. J Clin Oncol. (2015) 33:77381. doi: 10.1200/JCO.2014.57.4756

70. Lin PY, Sun L, Thibodeaux SR, Ludwig SM, Vadlamudi RK, Hurez VJ, et al. B7-H1-dependent sex-related differences in tumor immunity and immunotherapy responses. J Immunol. (2010) 185:2747-53. doi: 10.4049/jimmunol.1000496

71. Klein SL, Jedlicka A, Pekosz A. The Xs and $\mathrm{Y}$ of immune responses to viral vaccines. Lancet Infect Dis. (2010) 10:338-49. doi: 10.1016/S1473-3099(10) 70049-9

72. Kugel CH III, Douglass SM, Webster MR, Kaur A, Liu Q, Yin X, et al. Age correlates with response to anti-PD1, reflecting age-related differences in intratumoral effector and regulatory T-cell populations. Clin Cancer Res. (2018) 24:5347-56. doi: 10.1158/1078-0432.CCR-18-1116

73. Huang AC, Postow MA, Orlowski RJ, Mick R, Bengsch B, Manne S, et al. Tcell invigoration to tumour burden ratio associated with anti-PD-1 response. Nature. (2017) 545:60-5. doi: 10.1038/nature22079

74. Taylor RC, Patel A, Panageas KS, Busam KJ, Brady MS. Tumorinfiltrating lymphocytes predict sentinel lymph node positivity in patients with cutaneous melanoma. J Clin Oncol. (2007) 25:869-75. doi: 10.1200/JCO.2006.08.9755

75. Naito Y, Saito K, Shiiba K, Ohuchi A, Saigenji K, Nagura H, et al. CD8+ $\mathrm{T}$ cells infiltrated within cancer cell nests as a prognostic factor in human colorectal cancer. Cancer Res. (1998) 58:3491-4.

76. Diggs LP, Hsueh EC. Utility of PD-L1 immunohistochemistry assays for predicting PD-1/PD-L1 inhibitor response. Biomark Res. (2017) 5:12. doi: 10.1186/s40364-017-0093-8

77. Madore J, Vilain RE, Menzies AM, Kakavand H, Wilmott JS, Hyman J, et al PD-L1 expression in melanoma shows marked heterogeneity within and between patients: implications for anti-PD-1/PD-L1 clinical trials. Pigment Cell Melanoma Res. (2015) 28:245-53. doi: 10.1111/pcmr.12340

78. Liakou CI, Kamat A, Tang DN, Chen H, Sun J, Troncoso P, et al. CTLA4 blockade increases IFNgamma-producing CD4+ICOShi cells to shift the ratio of effector to regulatory $\mathrm{T}$ cells in cancer patients. Proc Natl Acad Sci USA. (2008) 105:14987-92. doi: 10.1073/pnas.0806075105

79. Koyama S, Akbay EA, Li YY, Herter-Sprie GS, Buczkowski KA, Richards WG, et al. Adaptive resistance to therapeutic PD-1 blockade is associated with upregulation of alternative immune checkpoints. Nat Commun. (2016) 7:10501. doi: 10.1038/ncomms10501

80. Mbongue JC, Nicholas DA, Torrez TW, Kim NS, Firek AF, Langridge $\mathrm{WH}$. The role of indoleamine 2, 3-dioxygenase in immune suppression and autoimmunity. Vaccines. (2015) 3:703-29. doi: 10.3390/vaccines3030703

81. Fallarino F, Grohmann U, Vacca C, Orabona C, Spreca A, Fioretti MC, et al. T cell apoptosis by kynurenines. Adv Exp Med Biol. (2003) 527:183-90.

82. Fallarino F, Grohmann U, You S, McGrath BC, Cavener DR, Vacca C, et al. Tryptophan catabolism generates autoimmune-preventive regulatory $\mathrm{T}$ cells. Transpl Immunol. (2006) 17:58-60. doi: 10.1016/j.trim.2006.09.017

83. Rubel F, Kern JS, Technau-Hafsi K, Uhrich S, Thoma K, Hacker G, et al. Indoleamine 2,3-dioxygenase expression in primary cutaneous 
melanoma correlates with breslow thickness and is of significant prognostic value for progression-free survival. J Invest Dermatol. (2018) 138:67987. doi: $10.1016 /$ j.jid.2017.09.036

84. Oaks MK, Hallett KM. Cutting edge: a soluble form of CTLA-4 in patients with autoimmune thyroid disease. J Immunol. (2000) 164:5015-8. doi: 10.4049/jimmunol.164.10.5015

85. Magistrelli G, Jeannin P, Herbault N, Benoit De Coignac A, Gauchat JF, Bonnefoy JY, et al. A soluble form of CTLA-4 generated by alternative splicing is expressed by nonstimulated human T cells. Eur J Immunol. (1999) 29:3596-602. doi: 10.1002/(SICI)1521-4141(199911)29:11<3596::AIDIMMU3596>3.0.CO;2-Y

86. Ryden A, Bolmeson C, Jonson CO, Cilio CM, Faresjo M. Low expression and secretion of circulating soluble CTLA-4 in peripheral blood mononuclear cells and sera from type 1 diabetic children. Diabetes Metab Res Rev. (2012) 28:84-96. doi: 10.1002/dmrr.1286

87. Sato S, Fujimoto M, Hasegawa M, Komura K, Yanaba $K$, Hayakawa I, et al. Serum soluble CTLA-4 levels are increased in diffuse cutaneous systemic sclerosis. Rheumatology. (2004) 43:1261-6. doi: 10.1093/rheumatology/keh303

88. Frigola X, Inman BA, Lohse CM, Krco CJ, Cheville JC, Thompson RH, et al. Identification of a soluble form of B7-H1 that retains immunosuppressive activity and is associated with aggressive renal cell carcinoma. Clin Cancer Res. (2011) 17:1915-23. doi: 10.1158/1078-0432.CCR-10-0250

89. Rossille D, Gressier M, Damotte D, Maucort-Boulch D, Pangault C, Semana G, et al. High level of soluble programmed cell death ligand 1 in blood impacts overall survival in aggressive diffuse large B-Cell lymphoma: results from a French multicenter clinical trial. Leukemia. (2014) 28:236775. doi: 10.1038/leu.2014.137

90. Wang L, Wang H, Chen H, Wang WD, Chen XQ, Geng QR, et al. Serum levels of soluble programmed death ligand 1 predict treatment response and progression free survival in multiple myeloma. Oncotarget. (2015) 6:4122836. doi: 10.18632 /oncotarget. 5682

91. Van Gorp H, Delputte PL, Nauwynck HJ. Scavenger receptor CD163, a Jackof-all-trades and potential target for cell-directed therapy. Mol Immunol. (2010) 47:1650-60. doi: 10.1016/j.molimm.2010.02.008

92. Jensen TO, Schmidt H, Moller HJ, Hoyer M, Maniecki MB, Sjoegren P, et al. Macrophage markers in serum and tumor have prognostic impact in American Joint Committee on Cancer stage I/II melanoma. J Clin Oncol. (2009) 27:3330-7. doi: 10.1200/jco.2008.19.9919

93. Zhang J, Basher F, Wu JD. NKG2D ligands in tumor immunity: two sides of a coin. Front Immunol. (2015) 6:97. doi: 10.3389/fimmu.2015.00097

94. Raulet DH. Roles of the NKG2D immunoreceptor and its ligands. Nat Rev Immunol. (2003) 3:781-90. doi: 10.1038/nri1199

95. Paschen A, Sucker A, Hill B, Moll I, Zapatka M, Nguyen XD, et al. Differential clinical significance of individual NKG2D ligands in melanoma: soluble ULBP2 as an indicator of poor prognosis superior to S100B. Clin Cancer Res. (2009) 15:5208-15. doi: 10.1158/1078-0432.CCR-09-0886

96. Chitadze G, Bhat J, Lettau M, Janssen O, Kabelitz D. Generation of soluble NKG2D ligands: proteolytic cleavage, exosome secretion and functional implications. Scand J Immunol. (2013) 78:120-9. doi: 10.1111/sji.12072

97. Maccalli C, Scaramuzza S, Parmiani G. TNK cells (NKG2D+ CD8+ or CD4+ T lymphocytes) in the control of human tumors. Cancer Immunol Immunother. (2009) 58:801-8. doi: 10.1007/s00262-008-0635-x

98. Nuckel H, Switala M, Sellmann L, Horn PA, Durig J, Duhrsen U, et al. The prognostic significance of soluble NKG2D ligands in B-cell chronic lymphocytic leukemia. Leukemia. (2010) 24:1152-9. doi: 10.1038/leu.2010.74

99. Groh V, Wu J, Yee C, Spies T. Tumour-derived soluble MIC ligands impair expression of NKG2D and T-cell activation. Nature. (2002) 419:7348. doi: 10.1038 /nature01112

100. Liu G, Lu S, Wang X, Page ST, Higano CS, Plymate SR, et al. Perturbation of NK cell peripheral homeostasis accelerates prostate carcinoma metastasis. $J$ Clin Invest. (2013) 123:4410-22. doi: 10.1172/JCI69369

101. Tannenbaum CS, Hamilton TA. Immune-inflammatory mechanisms in IFNgamma-mediated anti-tumor activity. Semin Cancer Biol. (2000) 10:11323. doi: $10.1006 /$ scbi.2000.0314

102. Bellucci R, Martin A, Bommarito D, Wang K, Hansen SH, Freeman GJ, et al. Interferon-gamma-induced activation of JAK1 and JAK2 suppresses tumor cell susceptibility to NK cells through upregulation of PD-L1 expression. Oncoimmunology. (2015) 4:e1008824. doi: 10.1080/2162402x.2015.1008824

103. Balkwill F. TNF-alpha in promotion and progression of cancer. Cancer Metastasis Rev. (2006) 25:409-16. doi: 10.1007/s10555-006-9005-3

104. Lin WW, Karin M. A cytokine-mediated link between innate immunity, inflammation, and cancer. J Clin Invest. (2007) 117:1175-83. doi: $10.1172 /$ jci31537

105. Guo Y, Xu F, Lu T, Duan Z, Zhang Z. Interleukin-6 signaling pathway in targeted therapy for cancer. Cancer Treat Rev. (2012) 38:90410. doi: $10.1016 /$ j.ctrv.2012.04.007

106. Hoejberg L, Bastholt L, Johansen JS, Christensen IJ, Gehl J, Schmidt H. Serum interleukin-6 as a prognostic biomarker in patients with metastatic melanoma. Melanoma Res. (2012) 22:287-93. doi: 10.1097/CMR.0b013e3283550aa5

107. Mortensen RF. C-reactive protein, inflammation, and innate immunity. Immunol Res. (2001) 24:163-76. doi: 10.1385/ir:24:2:163

108. Davis BP, Rothenberg ME. Eosinophils and cancer. Cancer Immunol Res. (2014) 2:1-8. doi: 10.1158/2326-6066.Cir-13-0196

109. Simson L, Ellyard JI, Dent LA, Matthaei KI, Rothenberg ME, Foster PS, et al. Regulation of carcinogenesis by IL-5 and CCL11: a potential role for eosinophils in tumor immune surveillance. J Immunol. (2007) 178:4222-9. doi: 10.4049/jimmunol.178.7.4222

110. Ishibashi S, Ohashi Y, Suzuki T, Miyazaki S, Moriya T, Satomi S, et al. Tumor-associated tissue eosinophilia in human esophageal squamous cell carcinoma. Anticancer Res. (2006) 26:1419-24.

111. Pretlow TP, Keith EF, Cryar AK, Bartolucci AA, Pitts AM, Pretlow TG II, et al. Eosinophil infiltration of human colonic carcinomas as a prognostic indicator. Cancer Res. (1983) 43:2997-3000.

112. Grivennikov SI, Greten FR, Karin M. Immunity, inflammation, and cancer. Cell. (2010) 140:883-99. doi: 10.1016/j.cell.2010.01.025

113. Hernandez C, Huebener P, Schwabe RF. Damage-associated molecular patterns in cancer: a double-edged sword. Oncogene. (2016) 35:593141. doi: 10.1038/onc.2016.104

114. Singel KL, Grzankowski KS, Khan A, Grimm MJ, D’Auria AC, Morrell $\mathrm{K}$, et al. Mitochondrial DNA in the tumour microenvironment activates neutrophils and is associated with worse outcomes in patients with advanced epithelial ovarian cancer. Br J Cancer. (2019) 120:207-17. doi: 10.1038/s41416-018-0339-8

115. Lee BM, Chung SY, Chang JS, Lee KJ, Seong J. The neutrophil-lymphocyte ratio and platelet-lymphocyte ratio are prognostic factors in patients with locally advanced pancreatic cancer treated with chemoradiotherapy. Gut Liver. (2018) 12:342-52. doi: 10.5009/gnl17216

116. Kiriu T, Yamamoto M, Nagano T, Hazama D, Sekiya R, Katsurada M, et al. The time-series behavior of neutrophil-to-lymphocyte ratio is useful as a predictive marker in non-small cell lung cancer. PLoS ONE. (2018) 13:e0193018. doi: 10.1371/journal.pone.0193018

117. Tanaka A, Sakaguchi S. Regulatory T cells in cancer immunotherapy. Cell Res. (2017) 27:109-18. doi: 10.1038/cr.2016.151

118. Sakaguchi S, Sakaguchi N, Shimizu J, Yamazaki S, Sakihama T, Itoh M, et al. Immunologic tolerance maintained by $\mathrm{CD} 25+\mathrm{CD} 4+$ regulatory $\mathrm{T}$ cells: their common role in controlling autoimmunity, tumor immunity, and transplantation tolerance. Immunol Rev. (2001) 182:18-32.

119. Onizuka S, Tawara I, Shimizu J, Sakaguchi S, Fujita T, Nakayama E. Tumor rejection by in vivo administration of anti-CD25 (interleukin-2 receptor alpha) monoclonal antibody. Cancer Res. (1999) 59:3128-33.

120. Weber R, Fleming V, Hu X, Nagibin V, Groth C, Altevogt P, et al. Myeloid-derived suppressor cells hinder the anti-cancer activity of immune checkpoint inhibitors. Front Immunol. (2018) 9:1310. doi: 10.3389/fimmu.2018.01310

121. Mantovani A. The growing diversity and spectrum of action of myeloid-derived suppressor cells. Eur J Immunol. (2010) 40:3317-20. doi: 10.1002/eji.201041170

122. Gabrilovich DI, Ostrand-Rosenberg S, Bronte V. Coordinated regulation of myeloid cells by tumours. Nat Rev Immunol. (2012) 12:253-68. doi: 10.1038/nri3175

123. Bedikian AY, Johnson MM, Warneke CL, Papadopoulos NE, Kim K, Hwu WJ, et al. Prognostic factors that determine the long-term survival 
of patients with unresectable metastatic melanoma. Cancer Invest. (2008) 26:624-33. doi: 10.1080/07357900802027073

124. Kelderman S, Heemskerk B, van Tinteren H, van den Brom RR, Hospers GA, van den Eertwegh AJ, et al. Lactate dehydrogenase as a selection criterion for ipilimumab treatment in metastatic melanoma. Cancer Immunol Immunother. (2014) 63:449-58. doi: 10.1007/s00262-014-1528-9

125. Taniguchi Y, Tamiya A, Isa SI, Nakahama K, Okishio K, Shiroyama T, et al. Predictive factors for poor progression-free survival in patients with non-small cell lung cancer treated with nivolumab. Anticancer Res. (2017) 37:5857-62. doi: 10.21873/anticanres. 12030

126. Alexandrov LB, Nik-Zainal S, Wedge DC, Aparicio SA, Behjati S, Biankin $\mathrm{AV}$, et al. Signatures of mutational processes in human cancer. Nature. (2013) 500:415-21. doi: 10.1038/nature12477

127. Topalian SL, Taube JM, Anders RA, Pardoll DM. Mechanism-driven biomarkers to guide immune checkpoint blockade in cancer therapy. Nat Rev Cancer. (2016) 16:275-87. doi: 10.1038/nrc.2016.36

128. Nakamura Y, Fujisawa Y, Tanaka R, Maruyama H, Ishitsuka Y, Okiyama $\mathrm{N}$, et al. Use of immune checkpoint inhibitors prolonged overall survival in a Japanese population of advanced malignant melanoma patients: retrospective single institutional study. J Dermatol. (2018) 45:13379. doi: $10.1111 / 1346-8138.14637$

129. Hayward NK, Wilmott JS, Waddell N, Johansson PA, Field MA, Nones $\mathrm{K}$, et al. Whole-genome landscapes of major melanoma subtypes. Nature. (2017) 545:175-80. doi: 10.1038/nature22071

130. Zhang Y, Sun Z, Mao X, Wu H, Luo F, Wu X, et al. Impact of mismatch-repair deficiency on the colorectal cancer immune microenvironment. Oncotarget. (2017) 8:85526-36. doi: 10.18632/oncotarget.20241

131. Lee V, Murphy A, Le DT, Diaz LA Jr. Mismatch repair deficiency and response to immune checkpoint blockade. Oncologist. (2016) 21:120011. doi: 10.1634/theoncologist.2016-0046

132. Goldstein J, Tran B, Ensor J, Gibbs P, Wong HL, Wong SF, et al. Multicenter retrospective analysis of metastatic colorectal cancer (CRC) with high-level microsatellite instability (MSI-H). Ann Oncol. (2014) 25:10328. doi: 10.1093/annonc/mdu100

133. Koopman M, Kortman GA, Mekenkamp L, Ligtenberg MJ, Hoogerbrugge $\mathrm{N}$, Antonini NF, et al. Deficient mismatch repair system in patients with sporadic advanced colorectal cancer. Br J Cancer. (2009) 100:26673. doi: $10.1038 /$ sj.bjc. 6604867

134. Overman MJ, Lonardi S, Wong KYM, Lenz HJ, Gelsomino F, Aglietta M, et al. Durable clinical benefit with nivolumab plus ipilimumab in DNA mismatch repair-deficient/microsatellite instability-high metastatic colorectal cancer. $J$ Clin Oncol. (2018) 36:773-9. doi: 10.1200/jco.2017.76.9901

135. Bhatt AP, Redinbo MR, Bultman SJ. The role of the microbiome in cancer development and therapy. CA Cancer J Clin. (2017) 67:32644. doi: $10.3322 /$ caac. 21398

136. Sivan A, Corrales L, Hubert N, Williams JB, Aquino-Michaels K, Earley ZM, et al. Commensal Bifidobacterium promotes antitumor immunity and facilitates anti-PD-L1 efficacy. Science. (2015) 350:10849. doi: $10.1126 /$ science.aac 4255

137. Schwarzenbach H, Hoon DS, Pantel K. Cell-free nucleic acids as biomarkers in cancer patients. Nat Rev Cancer. (2011) 11:426-37. doi: 10.1038/nrc3066

138. Garcia-Olmo DC, Dominguez C, Garcia-Arranz M, Anker P, Stroun M, Garcia-Verdugo JM, et al. Cell-free nucleic acids circulating in the plasma of colorectal cancer patients induce the oncogenic transformation of susceptible cultured cells. Cancer Res. (2010) 70:560-7. doi: 10.1158/0008-5472.Can-09-3513

139. Stroun M, Lyautey J, Lederrey C, Olson-Sand A, Anker P. About the possible origin and mechanism of circulating DNA apoptosis and active DNA release. Clin Chim Acta. (2001) 313:139-42.

140. Ascierto PA, Minor D, Ribas A, Lebbe C, O'Hagan A, Arya N, et al. Phase II trial (BREAK-2) of the BRAF inhibitor dabrafenib (GSK2118436) in patients with metastatic melanoma. J Clin Oncol. (2013) 31:320511. doi: 10.1200/JCO.2013.49.8691

141. Heitzer E, Ulz P, Geigl JB. Circulating tumor DNA as a liquid biopsy for cancer. Clin Chem. (2015) 61:112-23. doi: 10.1373/clinchem.2014.222679

142. Khagi Y, Goodman AM, Daniels GA, Patel SP, Sacco AG, Randall JM, et al. Hypermutated circulating tumor DNA: correlation with response to checkpoint inhibitor-based immunotherapy. Clin Cancer Res. (2017) 23:5729-36. doi: 10.1158/1078-0432.CCR-17-1439

143. Theodoraki MN, Yerneni SS, Hoffmann TK, Gooding WE, Whiteside TL. Clinical significance of PD-L1(+) exosomes in plasma of head and neck cancer patients. Clin Cancer Res. (2018) 24:896-905. doi: 10.1158/1078-0432.CCR-17-2664

144. Downey SG, Klapper JA, Smith FO, Yang JC, Sherry RM, Royal RE, et al. Prognostic factors related to clinical response in patients with metastatic melanoma treated by CTL-associated antigen-4 blockade. Clin Cancer Res. (2007) 13:6681-8. doi: 10.1158/1078-0432.CCR-07-0187

145. Freeman-Keller M, Kim Y, Cronin H, Richards A, Gibney G, Weber JS. Nivolumab in resected and unresectable metastatic melanoma: characteristics of immune-related adverse events and association with outcomes. Clin Cancer Res. (2016) 22:886-94. doi: 10.1158/1078-0432.CCR-15-1136

146. Khoja L, Atenafu EG, Templeton A, Qye Y, Chappell MA, Saibil S, et al. The full blood count as a biomarker of outcome and toxicity in ipilimumab-treated cutaneous metastatic melanoma. Cancer Med. (2016) 5:2792-9. doi: 10.1002/cam4.878

147. Kim HI, Kim M, Lee SH, Park SY, Kim YN, Kim H, et al. Development of thyroid dysfunction is associated with clinical response to PD-1 blockade treatment in patients with advanced non-small cell lung cancer. Oncoimmunology. (2017) 7:e1375642. doi: 10.1080/2162402X.2017.1375642

148. Rzepecki AK, Cheng H, McLellan BN. Cutaneous toxicity as a predictive biomarker for clinical outcome in patients receiving anticancer therapy. $J$ Am Acad Dermatol. (2018) 79:545-55. doi: 10.1016/j.jaad.2018.04.046

149. Kosche C, Mohindra N, Choi JN. Vitiligo in a patient undergoing nivolumab treatment for non-small cell lung cancer. JAAD Case Rep. (2018) 4:10424. doi: 10.1016/j.jdcr.2018.08.009

150. Liu RC, Consuegra G, Chou S, Fernandez Penas P. Vitiligo-like depigmentation in oncology patients treated with immunotherapies for nonmelanoma metastatic cancers. Clin Exp Dermatol. (2019) 2019:13867. doi: $10.1111 /$ ced.13867

151. Daly LE, Power DG, O'Reilly A, Donnellan P, Cushen SJ, O'Sullivan K, et al. The impact of body composition parameters on ipilimumab toxicity and survival in patients with metastatic melanoma. Br J Cancer. (2017) 116:310-7. doi: 10.1038/bjc.2016.431

152. Valpione S, Pasquali S, Campana LG, Piccin L, Mocellin S, Pigozzo J, et al. Sex and interleukin- 6 are prognostic factors for autoimmune toxicity following treatment with anti-CTLA4 blockade. J Transl Med. (2018) 16:94. doi: 10.1186/s12967-018-1467-x

153. Tarhini AA, Zahoor H, Lin Y, Malhotra U, Sander C, Butterfield LH, et al. Baseline circulating IL-17 predicts toxicity while TGF-betal and IL-10 are prognostic of relapse in ipilimumab neoadjuvant therapy of melanoma. $J$ Immunother Cancer. (2015) 3:39. doi: 10.1186/s40425-015-0081-1

154. Fujimura T, Sato Y, Tanita K, Kambayashi Y, Otsuka A, Fujisawa Y, et al. Serum levels of soluble CD163 and CXCL5 may be predictive markers for immune-related adverse events in patients with advanced melanoma treated with nivolumab: a pilot study. Oncotarget. (2018) 9:15542-51. doi: 10.18632/oncotarget.24509

155. Diehl A, Yarchoan M, Hopkins A, Jaffee E, Grossman SA. Relationships between lymphocyte counts and treatment-related toxicities and clinical responses in patients with solid tumors treated with PD-1 checkpoint inhibitors. Oncotarget. (2017) 8:114268-80. doi: 10.18632/oncotarget.23217

156. Fujisawa Y, Yoshino K, Otsuka A, Funakoshi T, Fujimura T, Yamamoto $\mathrm{Y}$, et al. Fluctuations in routine blood count might signal severe immunerelated adverse events in melanoma patients treated with nivolumab. $J$ Dermatol Sci. (2017) 88:225-31. doi: 10.1016/j.jdermsci.2017.07.007

157. Kimbara S, Fujiwara Y, Iwama S, Ohashi K, Kuchiba A, Arima H, et al. Association of antithyroglobulin antibodies with the development of thyroid dysfunction induced by nivolumab. Cancer Sci. (2018) 109:358390. doi: $10.1111 /$ cas. 13800

158. Stamatouli AM, Quandt Z, Perdigoto AL, Clark PL, Kluger H, Weiss SA, et al. Collateral damage: insulin-dependent diabetes induced with checkpoint inhibitors. Diabetes. (2018) 67:1471-80. doi: 10.2337/dbi18-0002

159. Oh DY, Cham J, Zhang L, Fong G, Kwek SS, Klinger M, et al. Immune toxicities elicted by CTLA-4 blockade in cancer patients are associated with 
early diversification of the T-cell repertoire. Cancer Res. (2017) 77:132230. doi: 10.1158/0008-5472.Can-16-2324

160. Dubin K, Callahan MK, Ren B, Khanin R, Viale A, Ling L, et al. Intestinal microbiome analyses identify melanoma patients at risk for checkpoint-blockade-induced colitis. Nat Commun. (2016) 7:10391. doi: 10.1038/ncomms10391

161. De Velasco G, Je Y, Bosse D, Awad MM, Ott PA, Moreira RB, et al. Comprehensive meta-analysis of key immune-related adverse events from CTLA-4 and PD-1/PD-L1 inhibitors in cancer patients. Cancer Immunol Res. (2017) 5:312-8. doi: 10.1158/2326-6066.Cir-16-0237

162. Eggermont AM, Chiarion-Sileni V, Grob JJ, Dummer R, Wolchok JD, Schmidt $\mathrm{H}$, et al. Adjuvant ipilimumab versus placebo after complete resection of high-risk stage III melanoma (EORTC 18071): a randomised, double-blind, phase 3 trial. Lancet Oncol. (2015) 16:522-30. doi: 10.1016/s1470-2045(15)70122-1

163. Perez-Gracia JL, Loriot Y, Rosenberg JE, Powles T, Necchi A, Hussain SA, et al. Atezolizumab in platinum-treated locally advanced or metastatic urothelial carcinoma: outcomes by prior number of regimens. Eur Urol. (2017) 2017:023. doi: 10.1016/j.eururo.2017.11.023

164. Antonia SJ, Lopez-Martin JA, Bendell J, Ott PA, Taylor M, Eder JP, et al. Nivolumab alone and nivolumab plus ipilimumab in recurrent small-cell lung cancer (CheckMate 032): a multicentre, open-label, phase 1/2 trial. Lancet Oncol. (2016) 17:883-95. doi: 10.1016/s1470-2045(16)30098-5

165. Khoja L, Day D, Wei-Wu Chen T, Siu LL, Hansen AR. Tumourand class-specific patterns of immune-related adverse events of immune checkpoint inhibitors: a systematic review. Ann Oncol. (2017) 28:237785. doi: $10.1093 /$ annonc/mdx 286

166. Weber JS, Dummer R, de Pril V, Lebbe C, Hodi FS. Patterns of onset and resolution of immune-related adverse events of special interest with ipilimumab: detailed safety analysis from a phase 3 trial in patients with advanced melanoma. Cancer. (2013) 119:1675-82. doi: 10.1002/ cncr.27969

167. Topalian SL, Sznol M, McDermott DF, Kluger HM, Carvajal RD, Sharfman $\mathrm{WH}$, et al. Survival, durable tumor remission, and long-term safety in patients with advanced melanoma receiving nivolumab. J Clin Oncol. (2014) 32:1020-30. doi: 10.1200/jco.2013.53.0105

168. Weber JS, Hodi FS, Wolchok JD, Topalian SL, Schadendorf D, Larkin J, et al. Safety profile of nivolumab monotherapy: a pooled analysis of patients with advanced melanoma. J Clin Oncol. (2017) 35:78592. doi: 10.1200/jco.2015.66.1389

169. Prado CM, Baracos VE, McCargar LJ, Reiman T, Mourtzakis M, Tonkin K, et al. Sarcopenia as a determinant of chemotherapy toxicity and time to tumor progression in metastatic breast cancer patients receiving capecitabine treatment. Clin Cancer Res. (2009) 15:29206. doi: 10.1158/1078-0432.Ccr-08-2242

170. Huillard O, Mir O, Peyromaure M, Tlemsani C, Giroux J, BoudouRouquette P, et al. Sarcopenia and body mass index predict sunitinib-induced early dose-limiting toxicities in renal cancer patients. Br J Cancer. (2013) 108:1034-41. doi: 10.1038/bjc.2013.58

171. Antoun S, Birdsell L, Sawyer MB, Venner P, Escudier B, Baracos VE. Association of skeletal muscle wasting with treatment with sorafenib in patients with advanced renal cell carcinoma: results from a placebo-controlled study. J Clin Oncol. (2010) 28:1054-60. doi: 10.1200/jco.2009.24.9730

172. Sabel MS, Lee J, Cai S, Englesbe MJ, Holcombe S, Wang S. Sarcopenia as a prognostic factor among patients with stage III melanoma. Ann Surg Oncol. (2011) 18:3579-85. doi: 10.1245/s10434-011-1976-9
173. Rollins KE, Tewari N, Ackner A, Awwad A, Madhusudan S, Macdonald IA, et al. The impact of sarcopenia and myosteatosis on outcomes of unresectable pancreatic cancer or distal cholangiocarcinoma. Clin Nutr. (2016) 35:11039. doi: 10.1016/j.clnu.2015.08.005

174. Blauwhoff-Buskermolen S, Versteeg KS, de van der Schueren MA, den Braver NR, Berkhof J, Langius JA, et al. Loss of muscle mass during chemotherapy is predictive for poor survival of patients with metastatic colorectal cancer. $J$ Clin Oncol. (2016) 34:1339-44. doi: 10.1200/jco.2015.63.6043

175. Schwinge D, Schramm C. Sex-related factors in autoimmune liver diseases. Semin Immunopathol. (2018) 2018:715. doi: 10.1007/s00281-018-0715-8

176. Fujimura T, Mahnke K, Enk AH. Myeloid derived suppressor cells and their role in tolerance induction in cancer. J Dermatol Sci. (2010) 59:16. doi: 10.1016/j.jdermsci.2010.05.001

177. Sosa A, Lopez Cadena E, Simon Olive C, Karachaliou N, Rosell R. Clinical assessment of immune-related adverse events. Ther Adv Med Oncol. (2018) 10:1758835918764628. doi: 10.1177/1758835918764628

178. Patel SA, Gooderham NJ. IL6 mediates immune and colorectal cancer cell cross-talk via miR-21 and miR-29b. Mol Cancer Res. (2015) 13:15028. doi: 10.1158/1541-7786.Mcr-15-0147

179. Abraham C, Cho J. Interleukin-23/Th17 pathways and inflammatory bowel disease. Inflamm Bowel Dis. (2009) 15:1090-100. doi: 10.1002/ibd.20894

180. Fujimura T, Kakizaki A, Furudate S, Aiba S. A possible interaction between periostin and $\mathrm{CD} 163(+)$ skin-resident macrophages in pemphigus vulgaris and bullous pemphigoid. Exp Dermatol. (2017) 26:1193-8. doi: 10.1111/exd.13157

181. Rumble JM, Huber AK, Krishnamoorthy G, Srinivasan A, Giles DA, Zhang $\mathrm{X}$, et al. Neutrophil-related factors as biomarkers in EAE and MS. J Exp Med. (2015) 212:23-35. doi: 10.1084/jem.20141015

182. Huebener P, Pradere JP, Hernandez C, Gwak GY, Caviglia JM, Mu X, et al. The HMGB1/RAGE axis triggers neutrophil-mediated injury amplification following necrosis. J Clin Invest. (2015) 125:539-50. doi: 10.1172/jci 76887

183. Berman D, Parker SM, Siegel J, Chasalow SD, Weber J, Galbraith S, et al. Blockade of cytotoxic T-lymphocyte antigen-4 by ipilimumab results in dysregulation of gastrointestinal immunity in patients with advanced melanoma. Cancer Immun. (2010) 10:11.

184. Da Gama Duarte J, Parakh S, Andrews MC, Woods K, Pasam A, Tutuka C, et al. Autoantibodies may predict immune-related toxicity: results from a phase i study of intralesional bacillus calmetteguerin followed by ipilimumab in patients with advanced metastatic melanoma. Front Immunol. (2018) 9:411. doi: 10.3389/fimmu.2018. 00411

185. Heidarian F, Alebouyeh M, Shahrokh S, Balaii H, Zali MR. Altered fecal bacterial composition correlates with disease activity in inflammatory bowel disease and the extent of IL8 induction. Curr Res Transl Med. (2019) 2019:002. doi: 10.1016/j.retram.2019.01.002

Conflict of Interest Statement: The author declares that the research was conducted in the absence of any commercial or financial relationships that could be construed as a potential conflict of interest.

Copyright (c) 2019 Nakamura. This is an open-access article distributed under the terms of the Creative Commons Attribution License (CC BY). The use, distribution or reproduction in other forums is permitted, provided the original author(s) and the copyright owner(s) are credited and that the original publication in this journal is cited, in accordance with accepted academic practice. No use, distribution or reproduction is permitted which does not comply with these terms. 